\title{
anat \\ Conceptual Design of a Novel Unmanned Ground Effect Vehicle (UGEV) and Flow Control Integration Study
}

\author{
Charalampos Papadopoulos ${ }^{1,2}$, Dimitrios Mitridis ${ }^{1,2}$ a and Kyros Yakinthos ${ }^{1, *(D)}$ \\ 1 Laboratory of Fluid Mechanics \& Turbomachinery, Department of Mechanical Engineering, Aristotle \\ University of Thessaloniki, 54124 Thessaloniki, Greece; charalpi@auth.gr (C.P.); dsmitrid@auth.gr (D.M.) \\ 2 UAV Integrated Research Center (UAV-iRC), Center for Interdisciplinary Research and Innovation (CIRI), \\ Aristotle University of Thessaloniki, 57001 Thermi, Greece \\ * Correspondence: kyak@auth.gr
}

check for updates

Citation: Papadopoulos, C.; Mitridis, D.; Yakinthos, K. Conceptual Design of a Novel Unmanned Ground Effect Vehicle (UGEV) and Flow Control

Integration Study. Drones 2022, 6, 25. https://doi.org/10.3390/

drones6010025

Academic Editor:

Abdessattar Abdelkefi

Received: 22 December 2021

Accepted: 11 January 2022

Published: 14 January 2022

Publisher's Note: MDPI stays neutral with regard to jurisdictional claims in published maps and institutional affiliations.

Copyright: (C) 2022 by the authors. Licensee MDPI, Basel, Switzerland. This article is an open access article distributed under the terms and conditions of the Creative Commons Attribution (CC BY) license (https:// creativecommons.org/licenses/by/ $4.0 /)$.

\begin{abstract}
In this study, the conceptual design of an unmanned ground effect vehicle (UGEV), based on in-house analytical tools and CFD calculations, followed by flow control studies, is presented. Ground effect vehicles can operate, in a more efficient way, over calm closed seas, taking advantage of the aerodynamic interaction between the ground and the vehicle. The proposed UGEV features a useful payload capacity of $300 \mathrm{~kg}$ and a maximum range of $300 \mathrm{~km}$ cruising at $100 \mathrm{kt}$. Regarding the aerodynamic layout, a platform which combines the basic geometry characteristics of the blended wing body (BWB), and box wing (BXW) configurations is introduced. This hybrid layout aims to incorporate the most promising features from both configurations, while it enables the UGEV to operate under adverse flight conditions of the atmospheric boundary layer of the earth. In order to enhance the performance characteristics of the platform, both passive and active flow control techniques are studied and incorporated into the conceptual design phase of the vehicle. For the passive flow control techniques, the adaptation of tubercles and wing fences is evaluated. Regarding the active flow control techniques, a wide range of morphing technologies is investigated based on performance and integration criteria. Finally, stability studies are conducted for the proposed platform.
\end{abstract}

Keywords: unmanned aerial vehicle (UAV); ground effect vehicle (GEV); flow control; morphing technologies; aircraft design; computational fluid dynamics (CFD)

\section{Introduction}

The current investigation focuses on the adaptation of state-of-the-art technologies to the design of a non-conventional configuration that will increase the efficiency of an aerial cargo transporting vessel, while taking into account the absence of runways. A combination of several different disciplines in a collaborative framework is employed, aiming to improve the possibility to obtain a more efficient platform. In sum, the proposed solution is to model a closed-wing blended wing body unmanned ground effect vehicle (UGEV) coupled with the use of passive and active flow control techniques. Considering its potential, the use of such an approach becomes extremely interesting in designing an efficient next-generation cargo transport unmanned aerial vehicle (UAV), by reducing the operating costs and the carbon dioxide emissions.

The ground effect vehicle idea is not new. From the 1960s to the 1980s, the concept of the ground effect vehicle (GEV) was introduced (Figure 1), mainly for military use and later for commercial concepts. Their main distinguishing factor is that they are designed to fly close to sea level, taking advantage of the ground effect and thus allowing for a greater efficiency [1]. The GEVs (also known as Ekranoplans) provided advantages for the military over conventional aircraft of the time, mainly due to the increased available payload capacity, greater fuel efficiency and low observability capabilities. Conversely, as civilian platforms, they featured a much quicker means of marine transport compared to ships. 
GEVs are technically flying boats, as they are equipped with a hull that allows take-off and landing from the water. Concerning the flight conditions, GEVs fly up to a few meters above sea level, exposing the flight envelope to high turbulence and gusts of the earth's atmospheric boundary layer [2]. The abrupt end of GEV development in the late 1980s led to a small amount of available relative research work, as none of these concepts ever reached serial production phase. This fact presents a conceptual design challenge; however, some literature research could be used as an initial point in the design $[1,3,4]$.

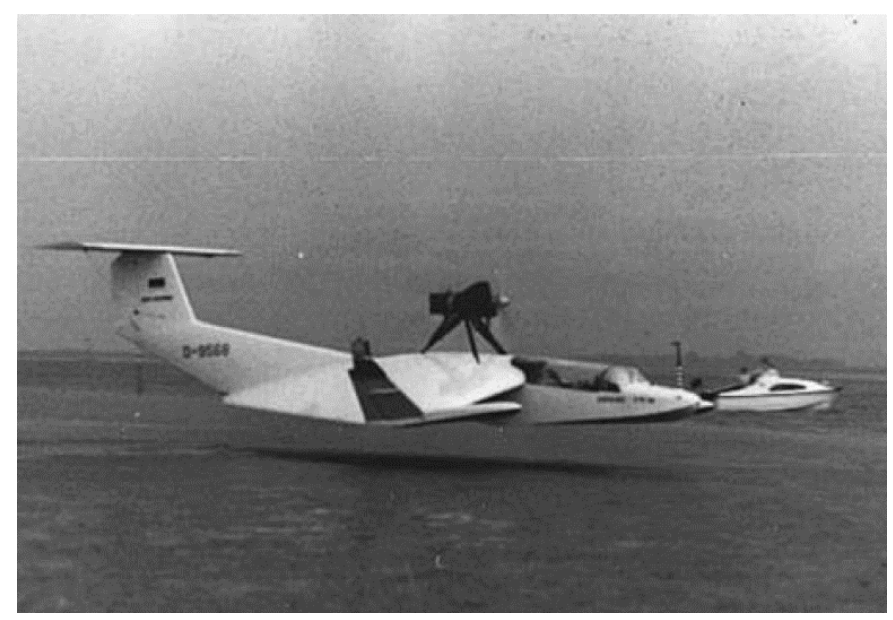

Figure 1. The Lippisch X-113 GEV [1] that was developed in the 1960s and 1970s.

The term ground effect (GE) is understood as an increase in the lift-to-drag ratio (L/D) of a wing, at cruise altitudes of less than the chord length of the wing, preferably less than 25\% [3]. As the wing nears the sea surface boundary, the free stream air is not allowed to expand under the wing, further increasing the static pressure and thus increasing the lift [4]. At the same time, the downwash velocity, due to the wing tip vortex, is reduced, which further contributes to the L/D ratio increase [1]. These theoretical claims regarding the ground effect are validated by both experiments and computational results [5]. The benefit of increased lift, coupled with the fact that there is no interaction with the water in cruise conditions, is an intriguing combination that has resurfaced scientific interest [4]. These characteristics qualify the GEVs as a competitive means of transport to and from islands and islets with no airport facilities, especially those located in closed calm seas.

Considering that GEVs can provide a heavier payload capacity compared to conventional aircraft due to the increased L/D ratio, it can be hypothesized that GEV platforms could potentially be used for cargo airlift missions. Historically, the main GEV development programs were focused on heavy weapon-carrying platforms, operating in closed and calm seas. By applying the same design principles and requirements to a civilian concept, a cargo GEV can be envisioned, enabling goods and mail to be transported efficiently and quickly across closed seas and relatively calm archipelagos. This concept could be greatly enhanced if coupled with the idea of a fixed-wing UAV, featuring a greater payload capacity due to the absence of crew and crew-related systems. Additionally, due to the absence of crew on board, fixed-wing UAVs present lower operating and maintenance costs, as well as the ability to operate under adverse or hazardous conditions without risking human lives [6].

A hybrid platform $[7,8]$ is introduced in this work, in order to better address the complex challenges of a ground effect vehicle [9]. The proposed novel UGEV combines the advantages of a blended wing body (BWB) platform, i.e., a tailless design that integrates wings and a fuselage, with the corrective additions of a box wing (BXW) platform, i.e., a closed box-like wing formation with no wing tips (Figure 2). The greatest advantage of the BWB platform is the $30 \%$ enhanced aerodynamic efficiency (in terms of L/D) [10] coupled with the smooth external geometry configuration that offers an enlarged internal 
volume [8]. In the frame of this work, it is also assumed that the increased reference area of the BWB platform could enhance the ground effect. Conversely, given the harsh and often unstable atmospheric conditions, the lack of a tail and vertical stabilizers presents a significant threat to the stability of the UGEV. In this sense, the BXW platform winglets extending from one wingtip to another can offer an alternative yaw control mechanism, while the tip-to-tip winglet connection can increase the stiffness of the whole structure [11]. Moreover, the adaptation of the BXW configuration can provide the much-needed tail section to enhance the lateral stability characteristics of the BWB platform. However, as the platform is novel, no other experimental or numerical results are in existence, as per the authors' knowledge.
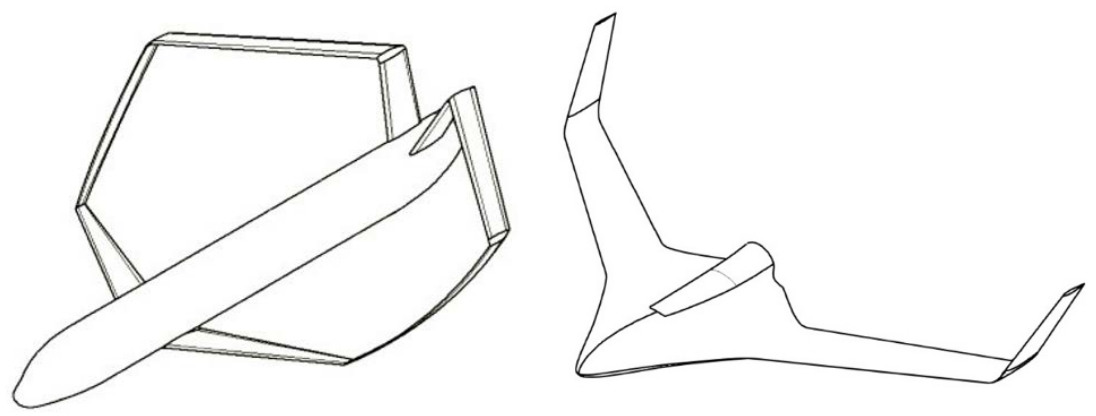

Figure 2. A typical BXW platform [7] (left) and a BWB platform [8] (right).

It is often that aerial platforms use flow control techniques (FCT) in order to further improve their stability and increase their aerodynamic efficiency (mainly by increasing lift and reducing drag). These techniques can be characterized as active or passive, depending on their need to use an external source of energy before being activated. The presence of gusts and high turbulence intensity conditions during the cruise mission segment further demonstrates the need for use of FCTs. The most well-known FCT in aeronautical applications is the winglet. However, the winglet is not applicable in this case, as the hybrid BWB-BXW platform already possesses a tip-to-tip winglet.

The sole FCT used on GEVs, per the authors' knowledge, is the wing fence (Figure 3). More specifically, the "Korabl Maket" GEV is equipped with leading edge wing fences. Wing fences are thin vanes or airfoils positioned on top of the wing and parallel to the free stream. They can be of various shapes and length, covering part of or the whole wing [12]. In the past, wing fences have been extensively studied at Reynolds numbers, relatively close to the ones of the GEV [12-15]. Through wind tunnel experiments, it has been shown that the wing fences have the ability to stop the spanwise flow development and flow detachment in tapered or swept wings [12,15], especially in high angles of attack. Therefore, wing fences secure the aerodynamic stability of the platform. The ease of construction and application, as well as the negligible added weight, supplement the aerodynamic advantages of the wing fences.

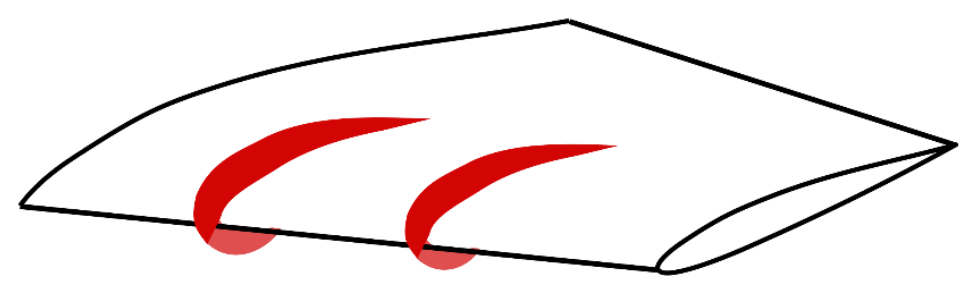

Figure 3. A pair of wing fences extending both on the suction side and pressure side, installed on a wing's surface.

An alternative way to passively control the flow is the use of tubercles (Figure 4), which are based on formations of arrays of sinusoidal bumps, located on the leading-edge region of the wing. This concept has been inspired by the humpback whale (Megaptera 
Novaeangliae) fin. Equipped with tubercles, the whale can achieve high manoeuvrability, despite its disproportionate size [16]. Tubercles are reported to outperform other FCTs such as vortex generators or even winglets, as they are not subjected to vibration loads, while at the same time they improve the lift to drag ratio [17]. Each bump creates a set of counter rotating vortices in its wake, which operates as a virtual wing fence and thus stops the spanwise flow and the flow detachment [18]. Various researchers [18,19] have summarized the available scientific data regarding the tubercles, which refer mainly to Reynolds numbers lower than the GEV's cruise Reynolds number. However, there are indications [20-22] that even in higher Reynolds number regimes, an increase in lift is possible.
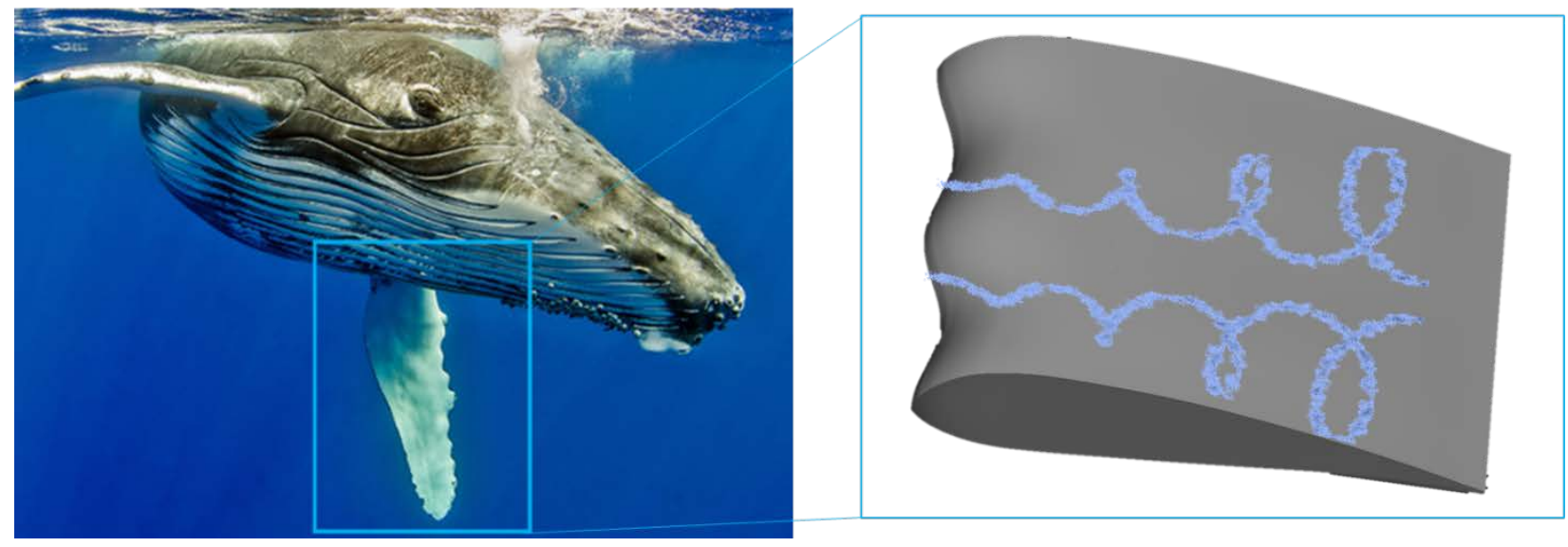

Figure 4. A sketch showing a possible flow mechanism explanation of the tubercles.

Another novel way of expanding the operational envelope of an aerial vehicle is to allow its external geometry to be morphed, enabling the platform to adapt to off-design flight conditions during its mission. More specifically, morphing refers to the ability to change the shape mid-flight and on demand, either on a 2D level (airfoil morphing) or on a 3D level (wing morphing) [23,24]. This way, optimal performance can be achieved at all mission segments (on- and off-design conditions), provided that the benefits in aerodynamic efficiency overcome the weight and complexity penalty. Wing morphing can increase aerodynamic performance and efficiency, while at the same time improve the manoeuvrability of the aerial vehicle. Dihedral (gull shape, Figure 5), twist and sweep angles can potentially be changed during flight, using actuators and flexible materials, in an attempt to optimize the wing loading (gust alleviation), lift and moment distributions, and to tune the aerodynamic centre location $[25,26]$. Nevertheless, the adaptation of morphing technologies to a GEV design could be proven beneficiary to counter the unstable conditions present at a low altitude above sea level, where they usually operate, and to enhance the flight capabilities of a GEV by expanding its operational envelope to even more off-design regions.

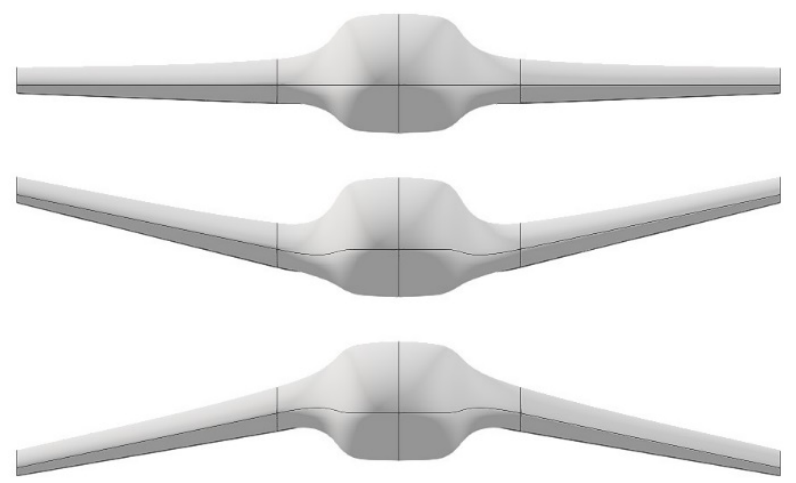

Figure 5. An indicative dihedral morphing concept. 
Researchers [1,4] have thus far summed up the available experience and work concerning the history, characteristics, and operation of a GEV; still, a definite GEV conceptual design methodology is not available in the current literature. Furthermore, as described in the literature review, there is a significant research gap, regarding the performance and efficiency of FCTs and morphing used on GEVs. In this way, the current study aims to design, at conceptual level, an unmanned ground effect vehicle (UGEV), using a combined methodology that incorporates design procedures from available literature into in-house sizing tools, along with high-fidelity modelling tools. The proposed platform, which includes distinct BWB and BXW features, will also adopt active and passive FCTs (i.e., morphing technologies, wing fences, tubercles). The resulting configuration aims to introduce a novel, more efficient approach regarding aerial cargo transportation over closed seas, with enhanced performance characteristics.

\section{Design Methodology}

\subsection{Methodology Overview}

For the conceptual design procedure, a custom in-house sizing methodology is employed (Figure 6), as the UGEV platform combines aspects of both a traditional aircraft and a flying boat, along with the additions of novel layout configurations, namely the BWB and BXW configurations. Being recognized as a more complex design procedure than a conventional one, the established design roadmap is reconsidered and replanned to include all the novel design features, as well as the interaction of the UGEV with the ground effect, and the integration of FCTs and morphing technologies. The design methodology is mainly based on well-established methods provided by aircraft design textbooks $[27,28]$, while incorporating statistical data and estimations from the available literature on GEVs [1,4]. An early approach regarding the methodology procedure has already been published by the authors [29], mainly focused on the analytical and numerical calculation of the baseline platform. The UGEV design methodology initiates with the listing of the basic mission requirements, including the mission profile and operational specifications, such as range, payload capacity, cruising speed, the ability to perform a "jump" (increase its altitude for a brief period to avoid an obstacle), etc.

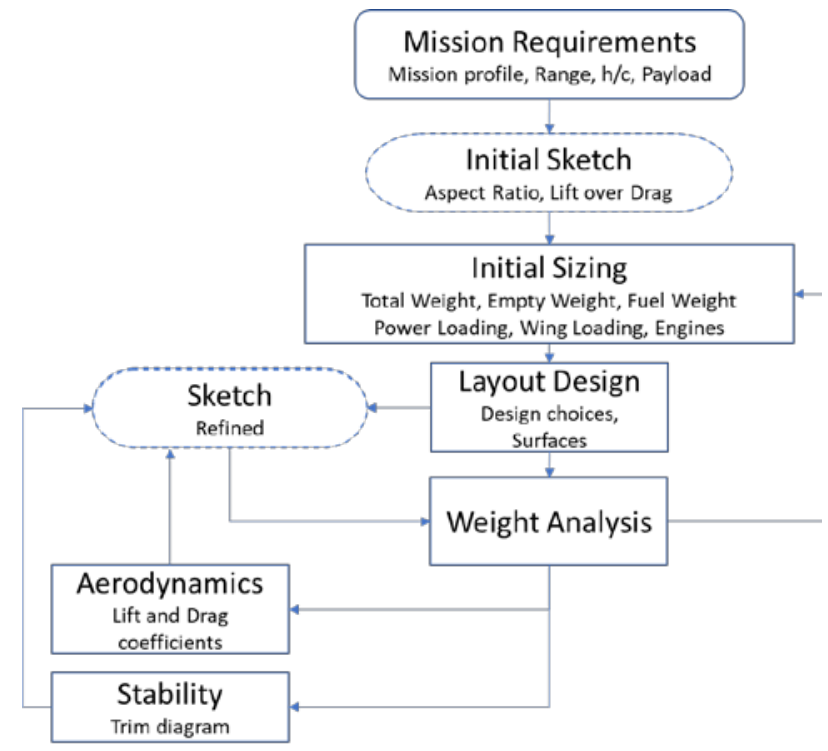

Figure 6. The conceptual UGEV design roadmap used in this work.

Having specified the mission requirements and bearing in mind that the platform should incorporate novel layout configurations, an initial sketch is drawn (Figure 7), followed by an initial platform sizing. The initial platform sizing step comprises weight, wing loading and power requirement studies and leads to the layout design step. Integrating all 
the design choices, the layout design results in a refined sketch, which in essence, is based on a parametric CAD file, producing a geometrical representation of the designed UGEV. A new configuration is created out of every layout design loop. At the same time, the weight analysis step, in which an extensive weight breakdown of the designed platform is calculated, provides the maximum take-off weight (MTOW) of each configuration. The next step in the UGEV conceptual design methodology is the aerodynamic analysis step, where lift, drag and moment coefficients are calculated. Lastly, stability and trim studies take place as a means of determining the feasibility of the designed layout in terms of stability and controllability during flight. The aerodynamic analysis of the UGEV platform takes place both for the jump state and the cruise state, with the main difference between them being the ground effect.

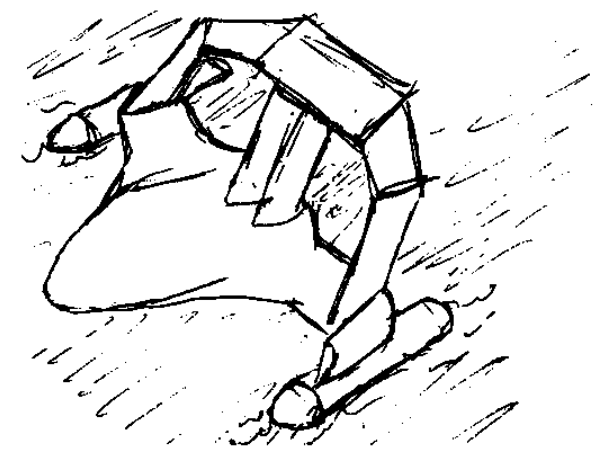

Figure 7. "Back of the napkin" sketch of the under-study UGEV platform.

\subsection{Mission Requirements and Initial Design Choices}

Concerning the mission requirements and profile, a first classification for the designed UGEV has been conducted in order to determine the target values for some key performance metrics (e.g., cruise speed, cruise altitude, payload capacity).

There are three subdivisions concerning a GEV [1]:

- $\quad$ Class A, where the GEV can operate only in ground effect;

- Class B, where the GEV can perform a small jump outside of the ground effect;

- Class C, where the GEV can operate both inside and outside of the ground effect.

In this work, a Class B UGEV is decided to be designed. In order to define the mission requirements of the UGEV platform, historic trend data [4] are analysed. As a test case, the proposed UGEV platform is selected to operate in Greek seas and airspace; thus, a design range of $300 \mathrm{~km}$ is deemed optimal for use in the Aegean Sea (Figure 8), as almost every islet is accessible from a major port (Athens, Thessaloniki, Heraklion) in this range. Using statistical data referring to GEVs [4], it can be suggested that the UGEV platform should have a cruising speed of about $150 \mathrm{~km} / \mathrm{h}$. 


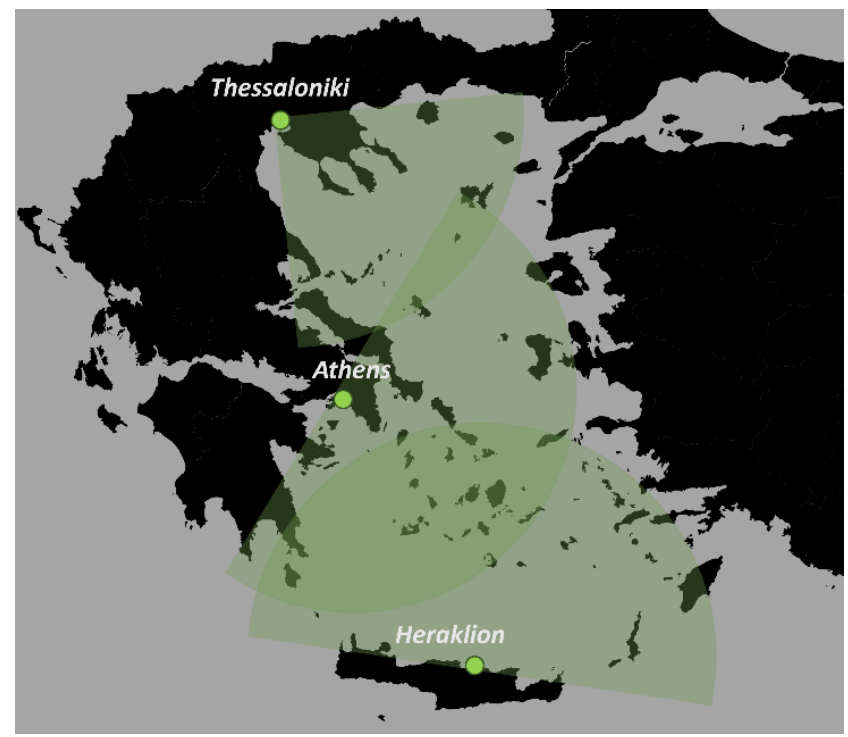

Figure 8. The range of the proposed UGEV operating from three major Greek ports is enough to serve the entire Aegean Sea.

With the literature suggestions in mind, a slightly more optimistic set of mission requirements regarding payload capacity and range is presented in Table 1.

Table 1. The mission requirements of the UGEV under study.

\begin{tabular}{cc}
\hline Payload Weight (kg) & $\mathbf{3 0 0}$ \\
\hline Range (km) & 300 \\
Cruise speed (knots) & 100 \\
Cruise altitude (m) & 0.36 \\
Span (m) & $\approx 7$ \\
Jump ability height (m) & 100 \\
\hline
\end{tabular}

Following again the literature suggestions that the cruise altitude for such payload should have a height-of-flight to mean aerodynamic chord (MAC) length ratio (h/c) of $15 \%$, the cruise altitude is selected to be $0.36 \mathrm{~m}$. Other literature suggestions defining the cruise altitude with the help of the height-of-flight to span ratio $(\mathrm{h} / \mathrm{b})$ lead to insufficient lift production and were therefore dismissed [29]. Additionally, the low annual mean wave height of the Aegean Sea [30] also contributes to this cruise altitude selection. However, this value is only an initial design constrain for the proposed UGEV. Adverse weather conditions accompanied with larger wave heights could be met with an increase in the flight altitude and consequently lower aerodynamic efficiency (reduced operational range). Studying the available statistical data [1], it is concluded that the volume of $300 \mathrm{~kg}$ could be accommodated in a $7 \times 7 \mathrm{~m}$ (width $\times$ length) vehicle; therefore, the span of the GEV is selected to be around $7 \mathrm{~m}$. Finally, as a class B UGEV, it is decided that the platform should be able to perform a $100 \mathrm{~m}$ jump such that large ships or rocky islets will not be an obstacle during missions (Figure 9). 


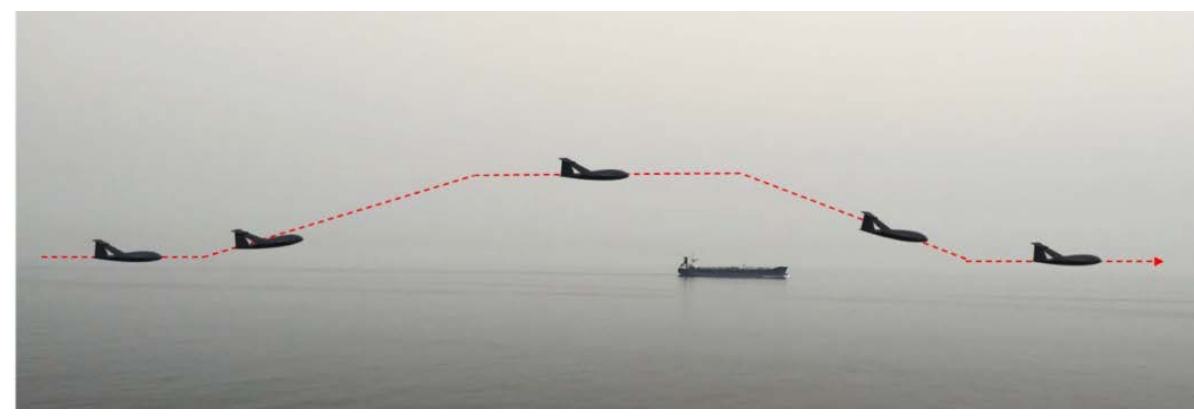

Figure 9. Indicative illustration of the UGEV platform avoiding a possible obstacle (e.g., ship) with a $100 \mathrm{~m}$ jump.

As discussed in a previously published authors' work [29], an in-house methodology and two alternative approaches are considered [1,4]. For each methodology, the range, payload, span, AR, and cruise speed are selected as fixed input values in order to compare the results in equal terms. Table 2 summarizes some characteristic values, calculated using different methodologies. The in-house approach is a detailed methodology based on the design of conventional aircrafts $[27,28]$ enriched with necessary modifications. Conversely, the work of Yun et al. [1] and Halloran and O'Meara [4] are GEV design methodologies, but they lack the level of detail and the robustness of the textbook based on in-house methodology, as they rely mostly on the scarce available literature data. However, the results of these methodologies appear to not deviate significantly from one another, except for the wing loading (W/S). In this conceptual phase, the lower wing loading of the novel BWB BXW configuration could possibly indicate better aerodynamic characteristics in terms of stall velocity, range, and endurance

Table 2. Characteristic design values as calculated from the different conceptual design textbooks.

\begin{tabular}{ccccccc}
\hline & $\begin{array}{c}\text { Payload } \\
\text { Fraction }\end{array}$ & $\begin{array}{c}\text { Take-Off } \\
\text { Weight (kg) }\end{array}$ & $\begin{array}{c}\text { Installed } \\
\text { Power (kW) }\end{array}$ & $\begin{array}{c}\text { Reference } \\
\text { Area (m2) }\end{array}$ & $\begin{array}{c}\text { Stall Speed } \\
\mathbf{( k m / h )}\end{array}$ & W/S (kg/m2) \\
\hline In-house & 0.28 & 1065 & 76 & 15.9 & 92.6 & 66.9 \\
\hline Yun et al. [1] & 0.25 & 1200 & 76 & 11.4 & 92.6 & 105.2 \\
$\begin{array}{c}\text { Halloran and } \\
\text { O'Meara [4] }\end{array}$ & 0.27 & 1100 & 100 & - & - & - \\
\hline
\end{tabular}

During the conceptual design, some special considerations are made. For example, the wing airfoil selection (reflexed MH family for the main body and lower wing and symmetrical for the upper wing) is driven both by aerodynamic and spatial criteria. More specifically, enough maximum thickness is ensured such that possible active flow control mechanisms could be stored inside the wings. In addition, the reflex camber of the $\mathrm{MH}$ airfoil family offers the much-needed pitch up aerodynamic moment that the tail-less BWB platform needs in order to be aerodynamically stable. For the rest of the platform's geometry (upper wing and vertical supports), symmetrical airfoils are used to reduce drag. Furthermore, the Oswald efficiency factor (e) is selected to match those of a box wing shape, as suggested by the literature [6]. In order to maximize the positive effects of the ground effect, the aspect ratio is kept at 4 , as there are strong literature indications for it [1,4]. In addition, aerodynamic teardrop-like compartments are placed at the wing connections aiming to possibly house morphing mechanisms (Figure 10). The main body of the designed UGEV is formed from airfoils with high thickness-to-chord ratio $(\mathrm{t} / \mathrm{c})$, providing sufficient internal space for the necessary flight systems, mission systems and payload. More specifically, a 1 $\times 1 \times 1.5 \mathrm{~m}$ orthogonal container is defined as the payload compartment. 

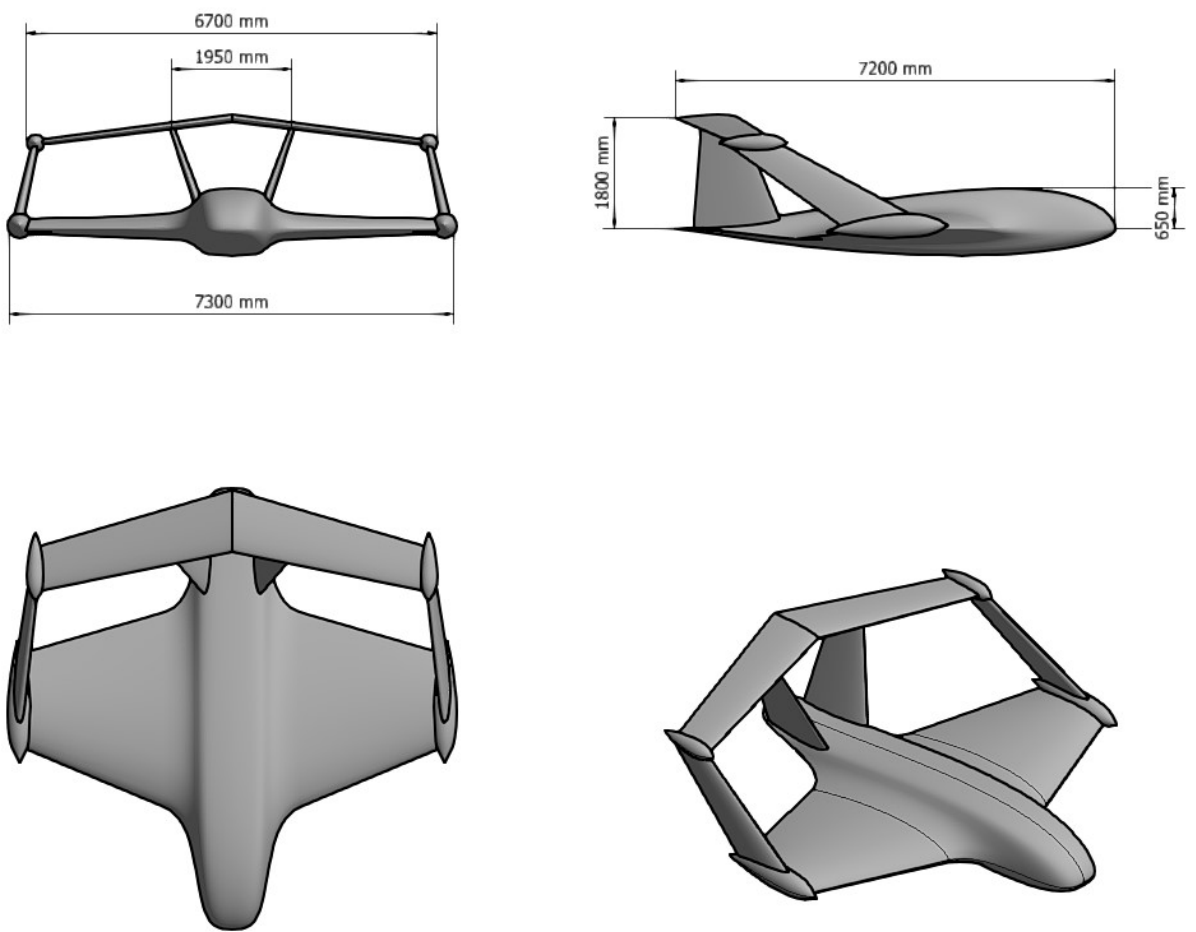

Figure 10. The external geometry of the UGEV platform as an initial outcome of the conceptual design.

Concerning the empennage of the proposed UGEV, it is designed to be part of the upper wing, as the BXW layout principles suggest. The UGEV will operate in the ground effect, and it is safe to assume that it will encounter high turbulent gusts. Thus, four large vertical surfaces are incorporated as a designer's choice to enhance the UGEV's directional stability in the high turbulent flight conditions. Supplementary, they can provide an enhanced control authority in case of engine failure, as the platform is designed to be powered by two piston engines coupled with propellers. These two engines are positioned in pylons suspended from the upper wing to provide a significant clearance from the water line and to avoid any potentially hazardous water spray. However, high mounted engines come with disadvantages, as they require a more rigid upper wing and wing supports, increasing the structural weight of the platform. After the initial geometry design is completed, a hull compartment and inverse winglets (functioning as secondary stability floaters) are placed in order to help the sea landing procedure (Figure 11).

During the analytical calculations of the coefficient of drag and coefficient of lift for the jump case, conventional tools [28] are modified to take into account the novel external geometry of the UGEV platform [29]. Concerning the analytical calculation of the coefficient of drag and coefficient of lift in the ground effect, no concrete guidelines exist. The authors have examined different proposed approaches [1,27], but as it has been previously highlighted, the above suggestions perform poorly [29]. 

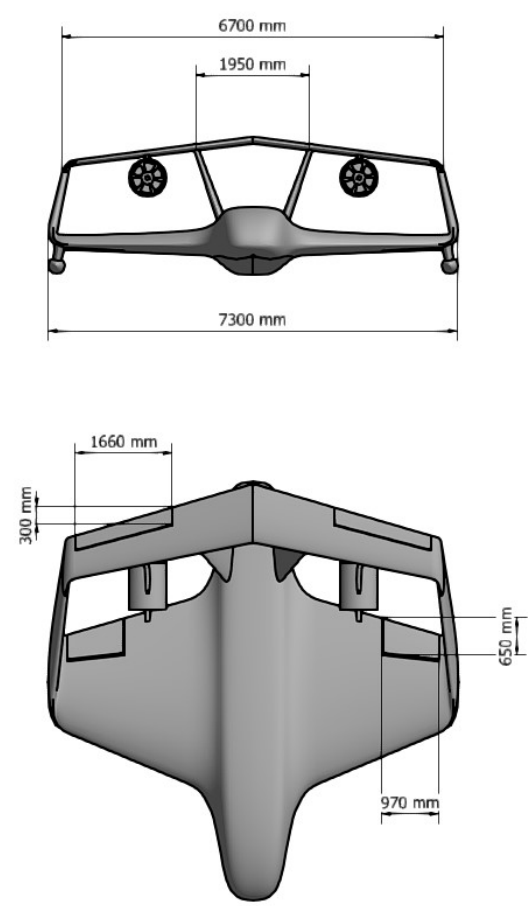
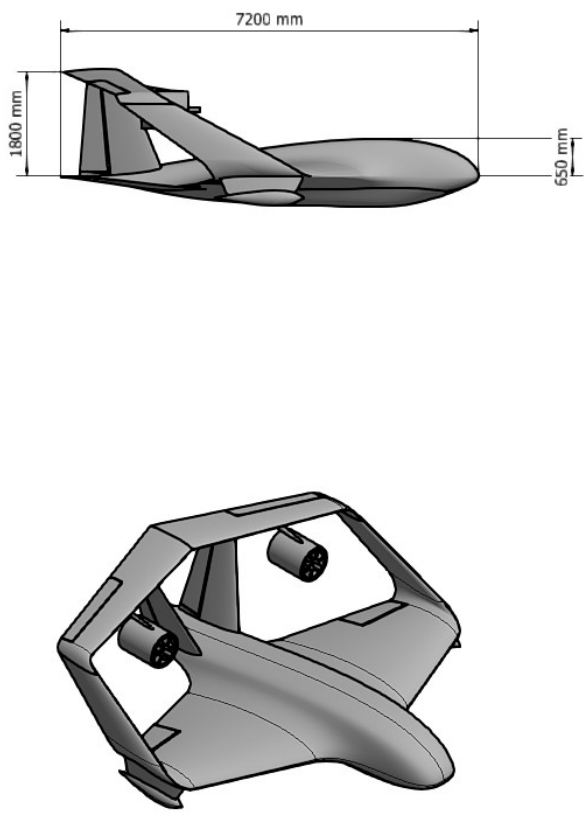

Figure 11. The improved external geometry of the UGEV platform.

The stability/control methodology is based on well-established textbook methods [28,31], which include the empennage sizing, longitudinal, lateral and directional stability studies, control surfaces sizing and trim studies. Most of the inputs needed for these studies, such as the centre of gravity (CG) position and the moments of inertia (MoI) matrix, the engines position, the maximum take-off weight and basic platform dimensions, are calculated from the $\mathrm{CAD}$ assembly. These methodologies are based on the kinematic equations governing the vehicle's motion during each mission segment, and the control surfaces are sized for the cruise flight scenario where their maximum authority is required (no take-off roll and high-g manoeuvres are present). Following, the trim diagram is drawn for the reference mission cruise segment with maximum payload and half fuel capacity. The most forward CG position is given for the full fuel capacity and, on the contrary, the most aft for no-fuel on board. The trim studies conclude by calculating the necessary trim angle of the control surfaces which satisfies the requirements for a zeroed moment coefficient $\left(\mathrm{C}_{\mathrm{m}}\right)$ along with the lift coefficient $\left(C_{L}\right)$ needed for cruise.

\subsection{CFD Methodology}

Regarding the CFD calculations, both the jump and the cruise scenario are considered. The meshes are constructed in the BETA CAE Systems ANSA Pre-Processor v20.1.0 mesh generator (Figure 12).

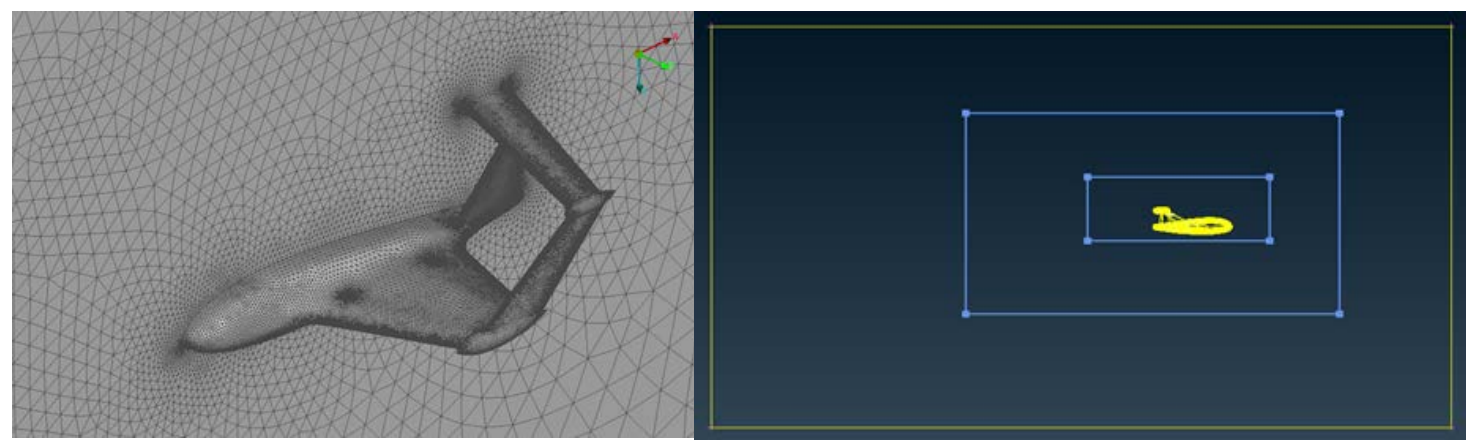

Figure 12. The constructed mesh (left) and the control volume of the CFD study (right). 
The first layer thickness is set at $1.6 \times 10^{-5} \mathrm{~m}$, ensuring a $\mathrm{y}^{+}$value lower than 1 in order to accurately predict the near wall region boundary layer behaviour. A total of 18 inflation layers are implemented for the boundary layer, while the computational grid consists of approximately 12,000,000 nodes and is a product of a 4-mesh grid independency study until a $2 \%$ difference in the $C_{D}$ value is reached (Table 3 ).

Table 3. Grid dependency study.

\begin{tabular}{ccc}
\hline Mesh & No. Computational Nodes & $\begin{array}{c}\text { \% Change of Cd Compared } \\
\text { to Previous Mesh }\end{array}$ \\
\hline Coarse & $5,400,000$ & - \\
Medium & $8,900,000$ & 7.6 \\
Fine & $12,200,000$ & 4.4 \\
Very fine & $17,600,000$ & 2 \\
\hline
\end{tabular}

Concerning the ground effect case, a moving wall boundary condition is used to model the sea surface. Fifteen additional inflation layers were added to the lower surface of the control volume in order to model the moving water surface (Figure 13, right).

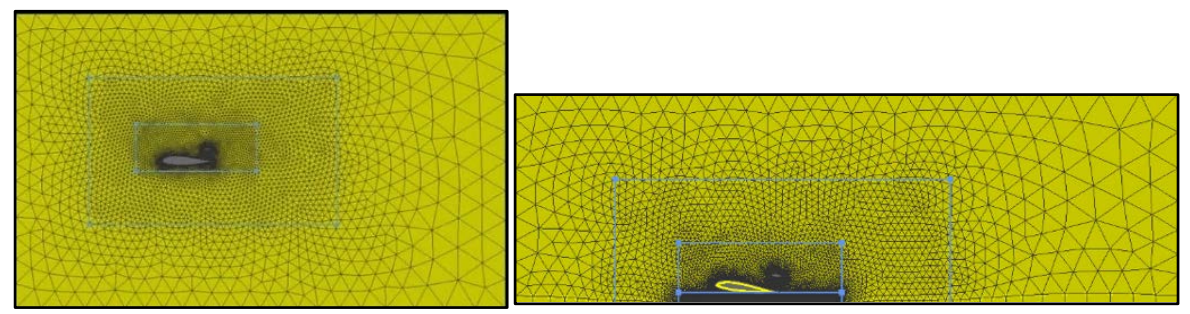

Figure 13. The constructed mesh for the cruise in jump case (left) and the ground effect case (right).

For the CFD calculations, the commercial Ansys Fluent software (ANSYS @ Scientific Research, Release 18.2) is used to solve the Reynolds-Averaged Navier-Stokes (RANS) equations. Both the Menter k- $\omega$ SST (2-equation) [32] and the transition $\gamma-\operatorname{Re}_{\theta}$ SST (4-equation) [33] turbulence models have proven their ability to accurately capture the complex tubercle-related flow phenomena in previous published works [20,34]. However, since the cruise Reynolds number of 10,000,000 (based on the MAC) is well beyond the boundary layer transition regime, the 2-equation k- $\omega$ SST model is selected. Regarding the turbulence parameters, the turbulence intensity at the inlet boundary is set at $10 \%$, which is considered a typical value for sea level [2].

\subsection{Flow Control Techniques Design Methodology}

\subsubsection{Tubercles}

The UGEV's 100 knots cruise speed corresponds to a Reynolds number of $10 \times 10^{6}$, a Reynolds regime with few published literature data regarding tubercles, as most of the work refers to Reynolds numbers smaller than $1 \times 10^{6}$ [18]. The main design parameters of the tubercles are the amplitude (A) and the wavelength (T). Swanson and Isaac [35] studied a tubercle array on a wing at a Reynolds number of $24 \times 10^{6}$ but with no encouraging results. Conversely, Dropkin et al. [36] reported a partial reduction on the coefficient of drag for a wing at Reynolds number $3 \times 10^{6}$ using Amplitude A equal to $12 \%$ of the MAC and wavelength $\mathrm{T}$ equal to $50 \%$ of the half-span. Studies about the positive outcome of the use of tubercles, but for significantly lower Reynolds numbers, have been reported by various researchers, such as Gross and Fasel [37], with A equal to 5\% of the MAC and T equal to 5\% of the half-span (Miklosovic et al. [17] and Bolzon et al. [38]).

With this literature input available, it was decided that tubercle arrays with A equal to $0.5 \%$ and $5 \%$ of the MAC, coupled with T equal to $25 \%$ and $50 \%$ of the half-span, should be examined (Figure 14). The tubercles are positioned spanwise alongside the whole of 
the main wing, as previous experience has shown that this kind of distribution offers the best outcome [20]. Due to the BWB nature of the platform, only the clean part of the wing was used for the tubercles application. Therefore, the $M A C_{c l n}$ and the $\operatorname{span}_{\mathrm{cln}}$ in this paragraph refer to the "clean" wing only. In order to have an integer number of tubercles and due to the leading-edge sweep, $\mathrm{T}$ was selected to be a factor of the $\operatorname{span}_{\mathrm{cln}}$ length, and therefore, $\mathrm{T}$ was changed from $25 \%$ to $18 \%$ and from $50 \%$ to $36 \%$. Finally, the authors intentionally kept the waviness formed by the adoption of tubercles, which starts from the leading edge and extends to the trailing edge, in order to enhance their effect. Table 4 sums up the basic geometry characteristics of the tubercles under study.

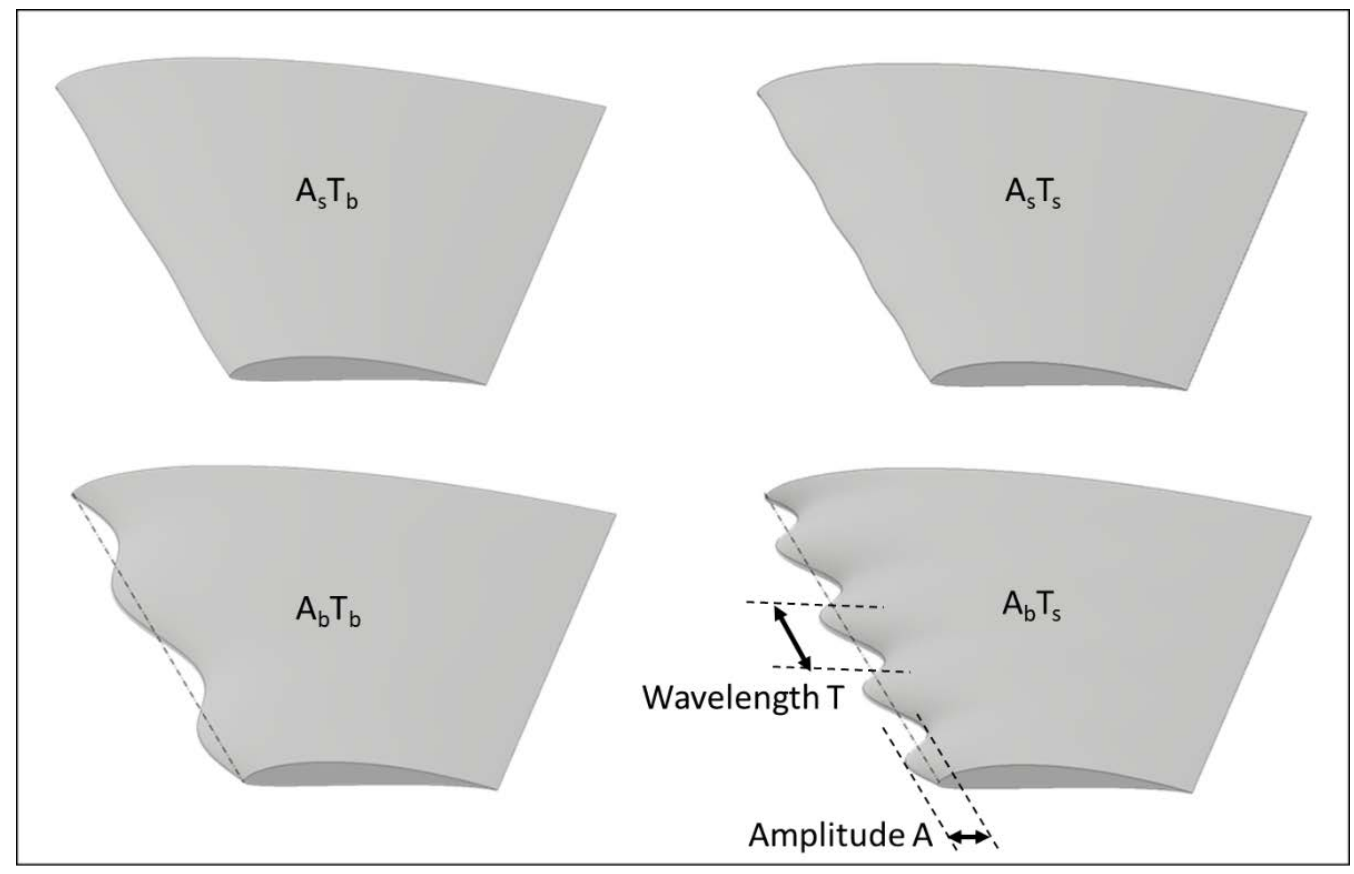

Figure 14. The four tubercle arrays under study.

Table 4. The basic characteristics of the tubercle cases under study.

\begin{tabular}{ccccc}
\hline Setup Name & $\mathbf{A}\left(\%\right.$ of $\left.\mathbf{M A C} \mathbf{C}_{\mathbf{c l n}}\right)$ & $\mathbf{A}(\mathbf{m})$ & $\mathbf{T}\left(\mathbf{\%}\right.$ of $\left.\mathbf{s p a n}_{\mathbf{c l n}}\right)$ & $\mathbf{T}(\mathbf{m})$ \\
\hline $\mathrm{A}_{\mathrm{s}} \mathrm{T}_{\mathrm{s}}$ & 0.5 & 0.012 & 18 & 0.66 \\
$\mathrm{~A}_{\mathrm{s}} \mathrm{T}_{\mathrm{b}}$ & 0.5 & 0.012 & 36 & 1.192 \\
$\mathrm{~A}_{\mathrm{b}} \mathrm{T}_{\mathrm{s}}$ & 5 & 0.12 & 18 & 0.66 \\
$\mathrm{~A}_{\mathrm{b}} \mathrm{T}_{\mathrm{b}}$ & 5 & 0.12 & 36 & 1.192 \\
\hline
\end{tabular}

These tubercle arrays are studied for angles of attack $4^{\circ}$ and $8^{\circ}$ for the jump case and for $2^{\circ}$ and $8^{\circ}$ for the ground effect case, corresponding to the cruise case and jump transition case, respectively. Furthermore, concerning the mesh construction for the tubercle cases, the same meshing criteria as in the baseline model is applied, ideally leading to the same mesh quality.

\subsubsection{Wing Fences}

Wing fence studies are more multivariable than tubercles and seem to be a more empirical than scientifically defined way of dealing with spanwise flow detachments. This is evident in the literature, where a plethora of differently shaped and sized fences exist [12-15]. Concerning the application of fences on BWB, a recent published work showed significant improvement for angles of attack greater than 12 degrees [39]. One basic categorization criterion is if the fence will extend to the pressure side or will remain only on the suction side of the wing. Therefore, two different wing fence types (Figure 15) 
are studied, i.e., one extending on both sides (80\% of the chord on the suction side and $20 \%$ on the pressure side) and one smaller, extending only on the suction side (50\% of the chord). Furthermore, for each case, a single fence (positioned on the $50 \%$ of the span in the spanwise direction) and a triple fence (positioned on the $25 \%, 50 \%$ and $75 \%$ of the span in the spanwise direction respectively) study will take place. The height of each wing fence was set as $5 \%$ of the chord, as the literature data suggest that further increasing the fence height has no positive effect [12].

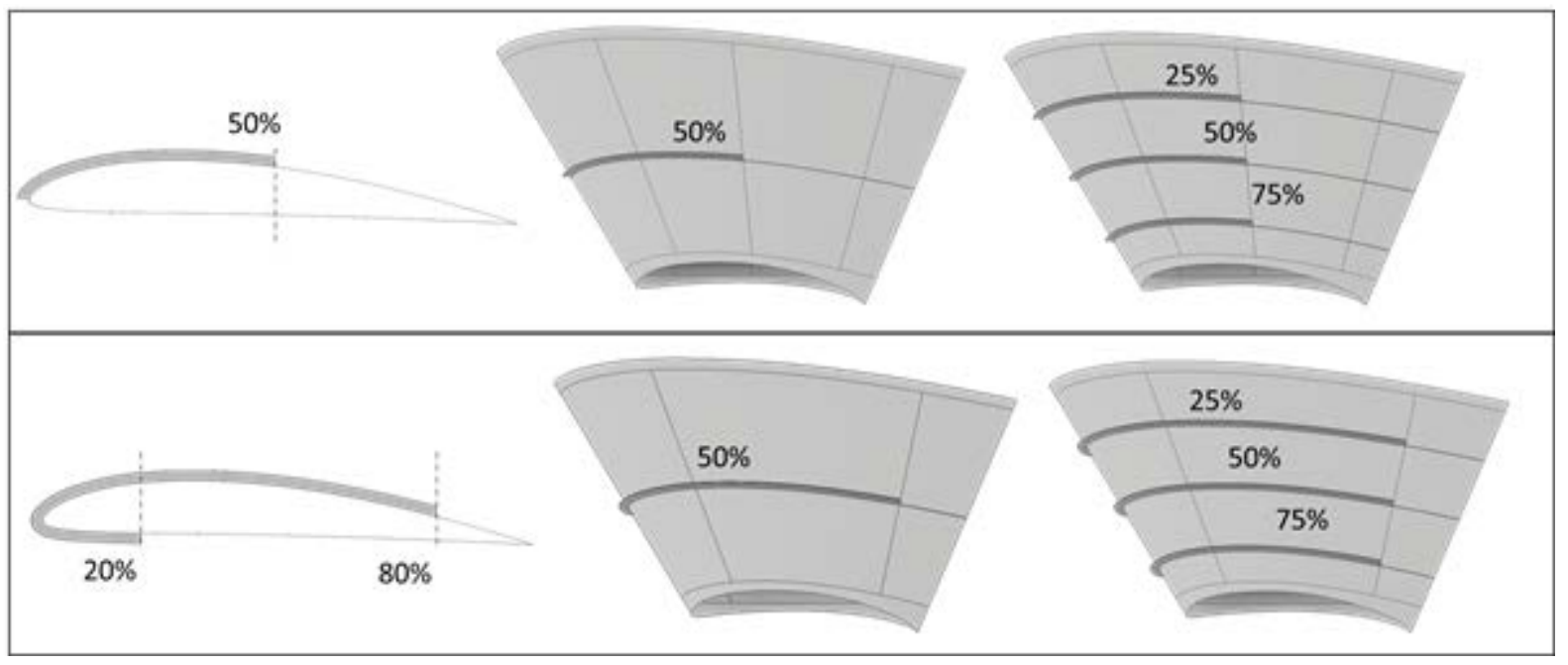

Figure 15. The four wing fence cases under study.

Table 5 summarizes the geometrical characteristics of the wing fence cases. All wing fence setups were studied for angles of attack $4^{\circ}$ and $8^{\circ}$ for the jump case and for $2^{\circ}$ and $8^{\circ}$ for the ground effect case, corresponding to the cruise case and jump transition case, respectively.

Table 5. The basic characteristics of the wing fence cases under study.

\begin{tabular}{ccc}
\hline Setup Name & Number of Fences & Installation \\
\hline WF1-1 & 1 & Suction and pressure side \\
WF1-3 & 3 & Suction and pressure side \\
WF2-1 & 1 & Suction side \\
WF2-3 & 3 & Suction side \\
\hline
\end{tabular}

\subsubsection{Morphing}

The morphing technologies evaluation methodology consists of the available technologies overview and the listing of the benefits and penalties introduced to the overall design. Based on the literature review, the in-house conceptual calculations and the platform compatibility studies, an initial qualitative evaluation is performed (Table 6). It is apparent that, in this stage, the evaluation procedure is subjective; nevertheless, it offers the advantage of ruling out incompatible technologies from the beginning. The reader could have evaluated the listed technologies differently for another reference UGEV platform. Having selected the gull and hull morphing technologies as the best suited to the UGEV platform, a concept of each one is studied, and a weight analysis is carried out to determine if the exploited benefits are counterbalanced by the induced weight penalty (due to the presence of the mechanism) or not. 
Table 6. Morphing technologies list.

\begin{tabular}{cccc}
\hline Technology & $\begin{array}{c}\text { Technology } \\
\text { Maturity }\end{array}$ & Weight Penalty & $\begin{array}{c}\text { Further } \\
\text { Investigation }\end{array}$ \\
\hline Span morphing & Very low & Very high & No \\
Spanwise bending & Low & High & No \\
Sweep morphing & Very high & Low & No \\
Chord morphing & Very low & Very high & No \\
Variable dihedral (gull morphing) & High & Low & Yes \\
Morphing winglets & Very high & Low & No \\
Twist morphing & Low & High & No \\
Camber morphing & Low & High & No \\
Airfoil thickness & Very low & High & No \\
Special devices (hull morphing) & High & Low & Yes \\
\hline
\end{tabular}

\section{Results}

In this section, a detailed presentation of the results is made. The baseline model is tested for various altitudes in order to examine the effect of the ground on the aerodynamic characteristics (lift curve slope, drag polar, and lift-to-drag ratio) as presented in Figure 16. As the cruising altitude decreases, starting from the $100 \mathrm{~m}$ jump altitude down to the 0.36 $\mathrm{m}$ height, a significant upwards shift of the lift curve is observed. Meanwhile, as the coefficient of drag does not change much, the increased lift provides a better overall efficiency and an extended flight envelope. More specifically, the lift-to-drag ratio increases almost 1.5 times in the GE compared with the jump conditions. This is qualitatively in accordance with available experimental and numerical literature data for conventional GEV platforms [5]. However, the presented computational results concern the conceptual design phase, and the limited accuracy of the calculations should be kept in mind [27].
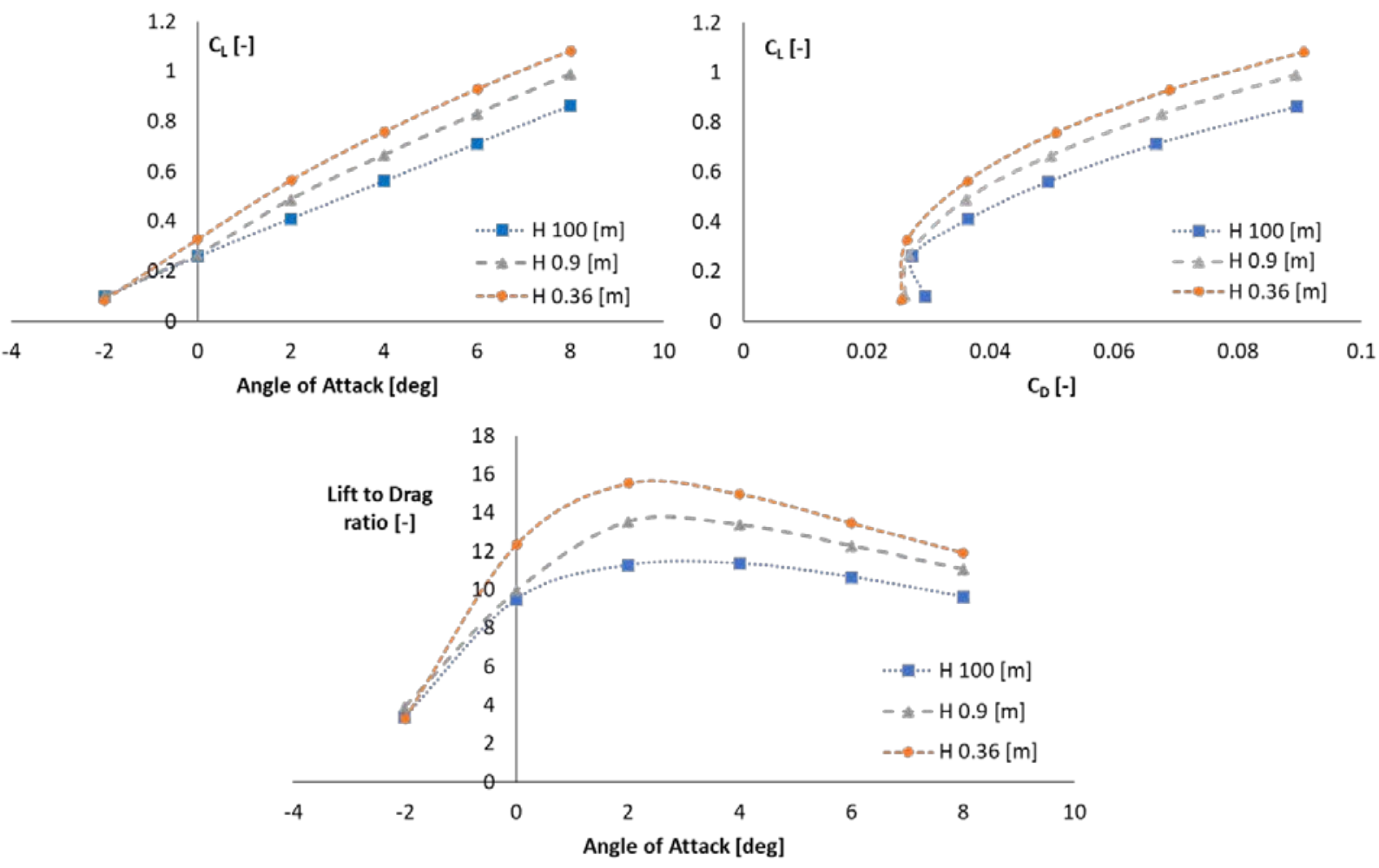

Figure 16. The lift curve slope (upper left), the drag polar (upper right) and the lift-to-drag ratio (bottom) between the different cruising altitudes for the baseline geometry, as per the CFD calculations. 
This difference can be supported by visualizing the flow around the baseline platform (Figure 17). It can be observed that the pressure below the UGEV in the ground effect is significantly increased, augmenting the lift capabilities of the platform.

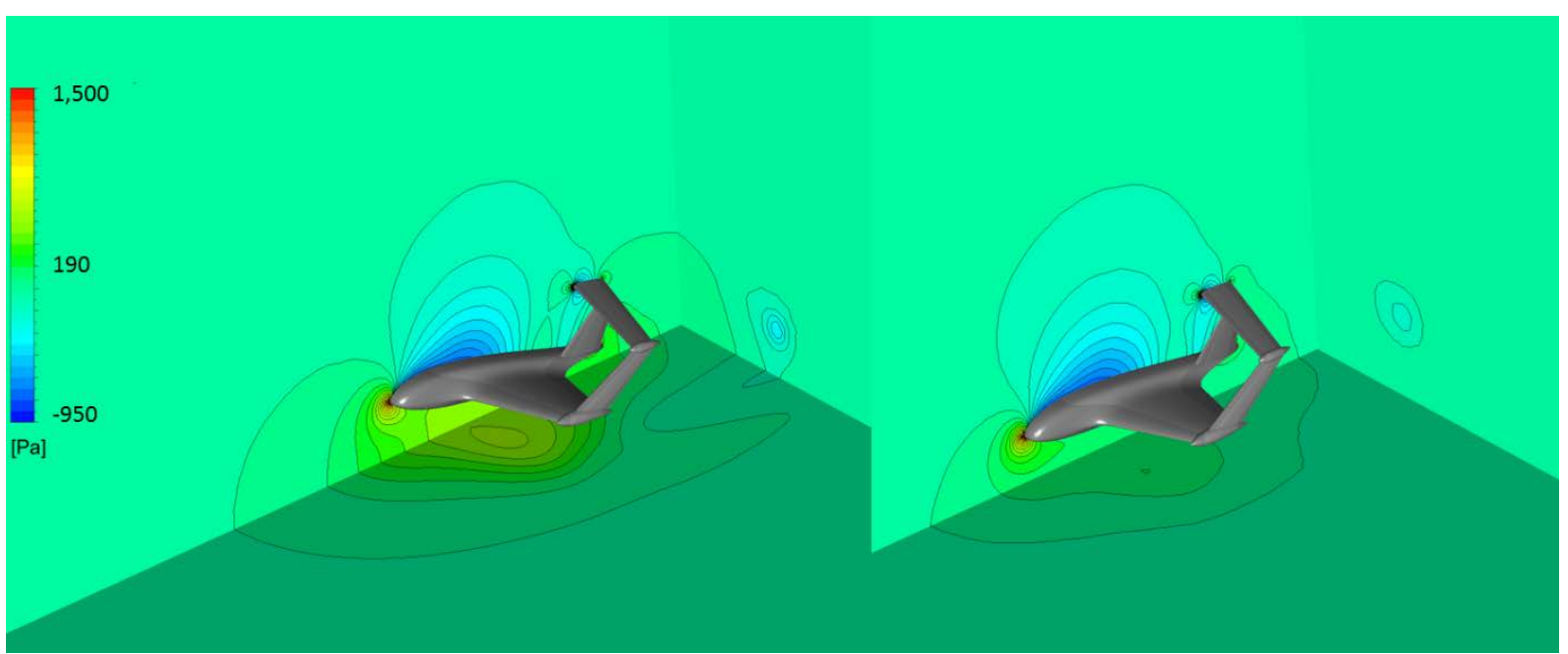

Figure 17. The baseline platform in the ground effect (left) and in jump conditions (right) for $8^{\circ}$ angle of attack.

Upon finalizing the external geometry of the platform, CFD calculations are again carried out and compared with the baseline model. Figure 18 presents these comparisons, where it can be observed that the streamlined body of the finalized geometry has little to no effect on the lift curve slope, but it significantly reduces the drag and simultaneously increases the overall efficiency.
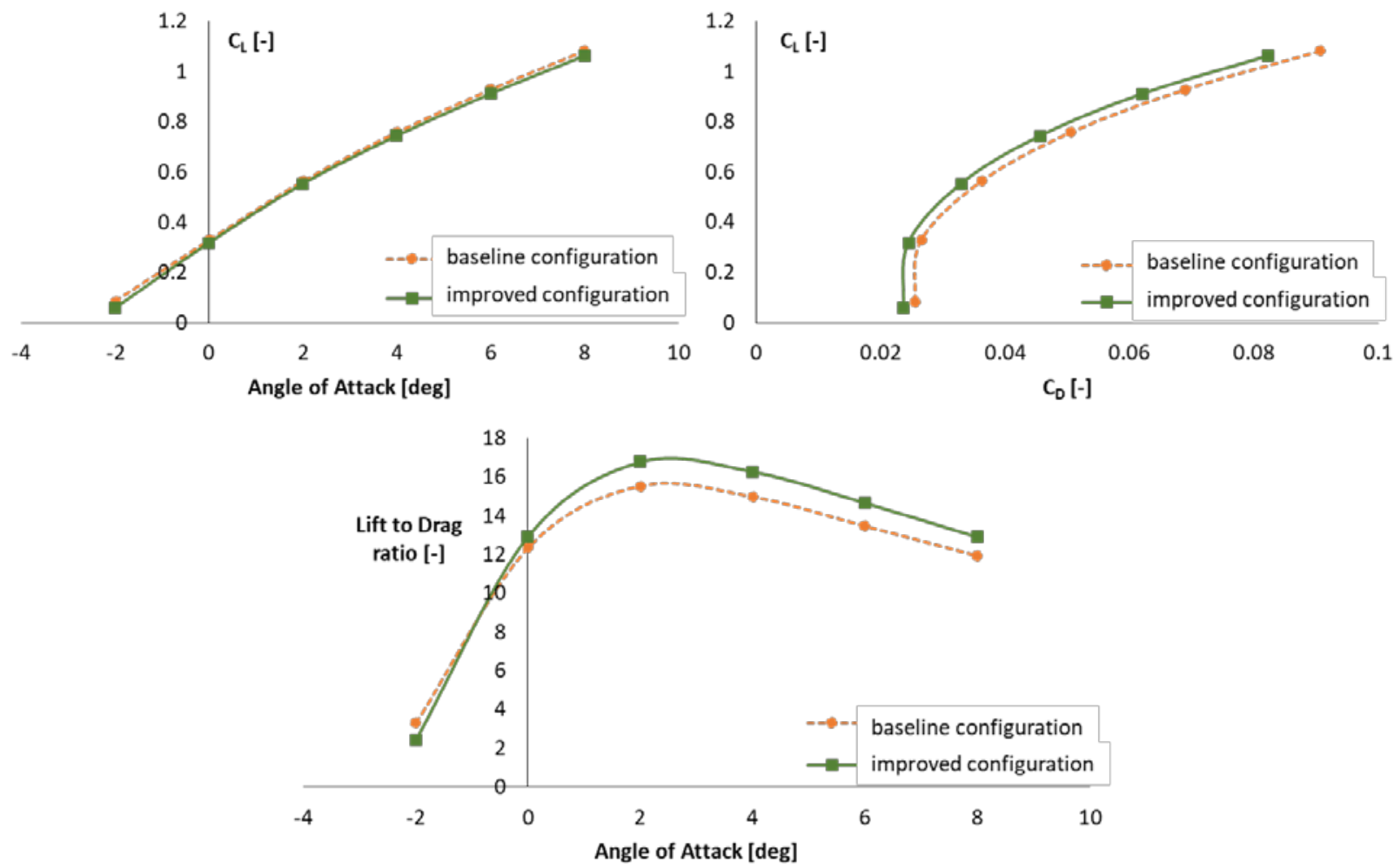

Figure 18. The lift curve slope (upper left), the drag polar (upper right) and the lift-to-drag ratio (bottom) between the baseline and the finalized geometry at the cruising altitude of $\mathrm{H} 0.36 \mathrm{~m}$ as per the CFD calculations. 
The CFD computations have shown that the addition of FCTs can help to increase the UGEV payload weight. More specifically, the tubercle array $\mathrm{A}_{\mathrm{s}} \mathrm{T}_{\mathrm{b}}$ provides greater lift results out of all cases, enabling an up-to-30 kg increase, or $10 \%$ of the total payload (Figure 19). This increase in generated lift comes with an increase in drag, which is considered negligible, as it is less than 3\%. However, as the lift increase is around $1 \%$ different from the baseline, further integration of these FCTs in the preliminary design phase for the proposed UGEV needs to be validated with the use of experiments.

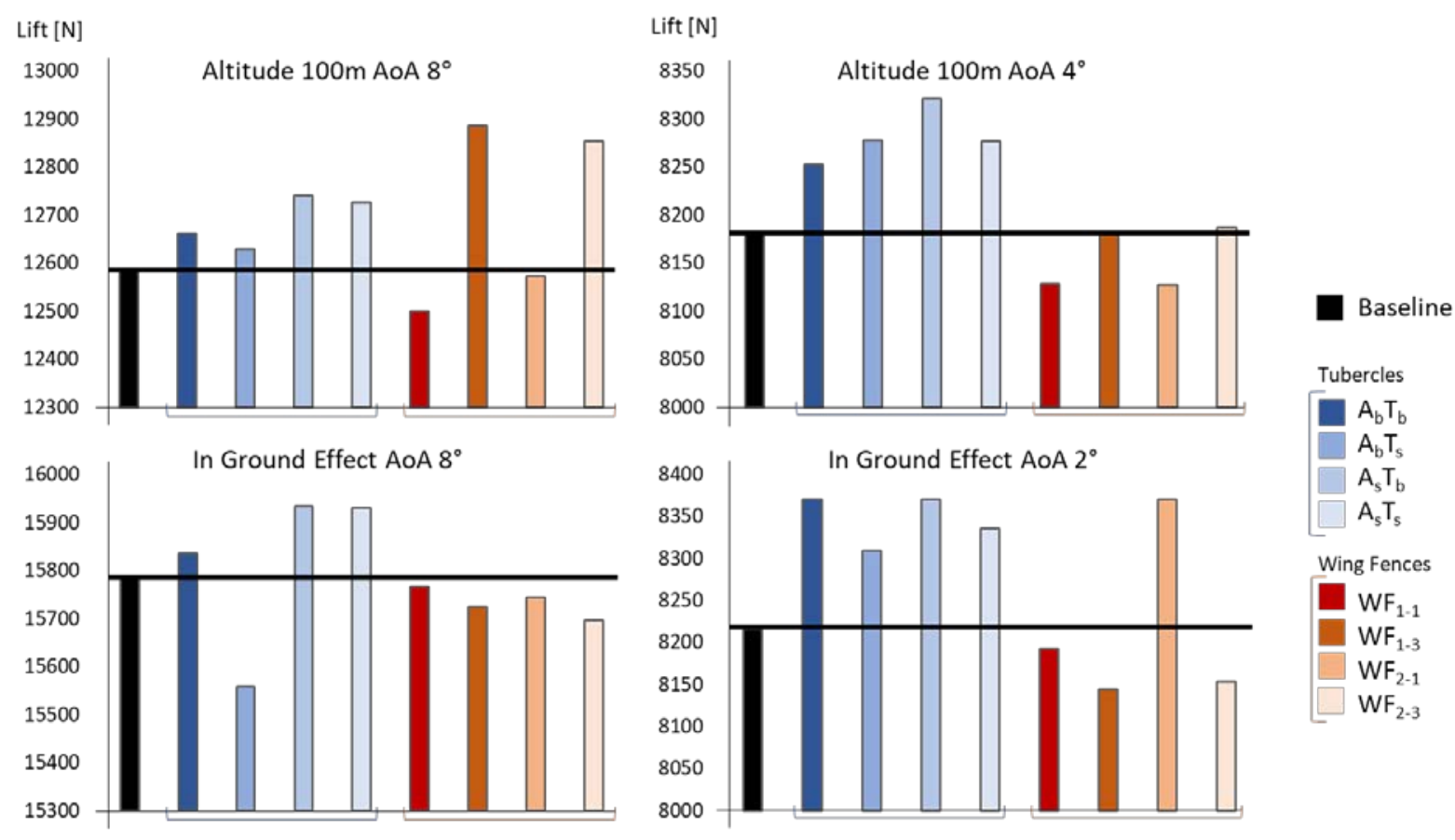

Figure 19. The generated lift for the various FCTs (green shades: tubercles, orange shades: wing fences) compared to the baseline as modelled for the half-symmetrical UGEV model.

The rest of the tubercle arrays and wing fence setups could be alternatively used to achieve optimization in different kinds of missions. For example, the WF2-1 setup can achieve the best lift-to-drag ratio (L/D) by increasing the aerodynamic efficiency by almost $2 \%$ in cruise conditions.

The effect of these FCT can also be observed by visualizing the wall shear stress on top of the UGEV (Figure 20). Both the tubercles and wing fences appear to have an effect by changing the distribution of the wall shear stresses and consequently the skin friction and the lift distribution. 

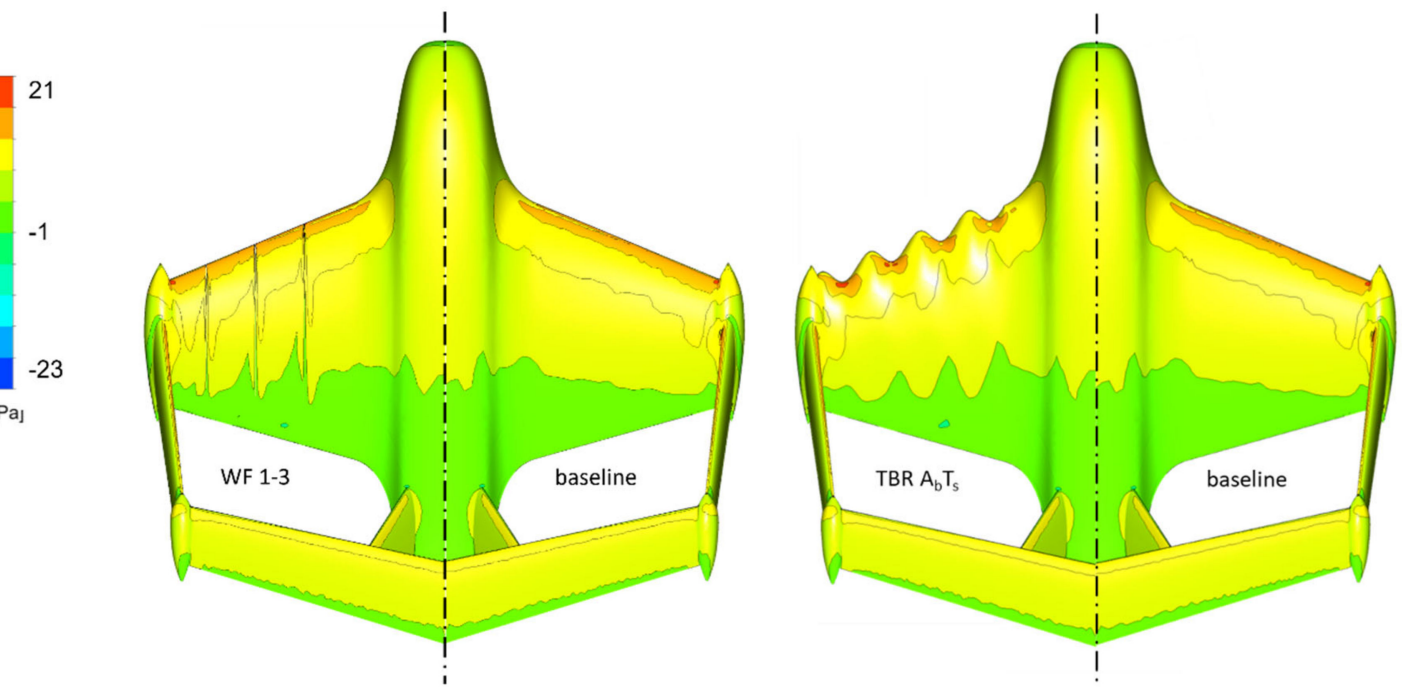

Figure 20. Indicative wall shear stress contours for a tubercle and a wing fence case compared to the baseline.

Concerning the morphing technologies evaluation studies, only two candidate morphing technologies are suitable to be integrated onto the UGEV platform. Namely, a dihedral morphing (gull morphing) mechanism and a morphing hull structure are selected, featuring a means of extending the platform's geometry during take-off and landing and retracting it during cruising. This way, the floating mechanisms of the craft are integrated while minimizing the drag penalty. In the gull morphing concept (Figure 21 left), the wing tip floaters lower towards the sea (creating an anhedral angle), making contact with the water earlier and thus minimizing the need for increased floater volume. This concept requires at least four hinging points per wing and thus implements a quite severe weight and complexity penalty to the craft. Conversely, the morphing hull concept uses a flexible lower skin supported by a series of hydraulic pistons in order to extend and retract the hull (Figure 21 right).
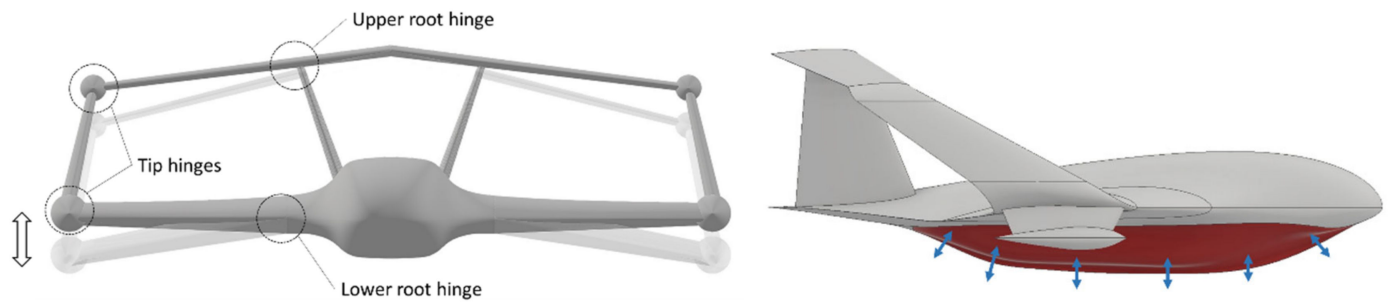

Figure 21. The gull morphing concept (left) and hull morphing concept (right).

The overall weight for each one of the morphing mechanisms is estimated based on conceptual sizing studies. The gull morphing concept takes into account both the aerodynamic bending loads during the flight and the hydrodynamic loads during touch down. According to general regulations regarding seaplanes [40], the overall structure of the UGEV has to be able to withstand loads at $2.33 \mathrm{~g}$ during landing. Based on these, analytical structural sizing calculations are executed for the main parts of each mechanism, providing their geometrical characteristics. Having specified the materials used for the morphing mechanisms (primarily aluminium alloys), the total added weight can be estimated at 46 $\mathrm{kg}$ for the gull morphing concept (including supports, actuators, hinges, and miscellaneous components) and at $8 \mathrm{~kg}$ for the morphing hull concept (again, all components included). As it turns out, the gull shape morphing comes with a heavy weight penalty, and it is not going to be included to the final configuration in contrast to the morphing hull mechanism. 
A comparative aerodynamic study between the extended and the retracted hull geometries (Figure 22) is also carried out. The extended hull suffers a 3\% reduction in the lift and a further $1 \%$ increase in the drag. This slightly worse behaviour is assumed to not have any negative effect on the mission planning, given that a streamlined design is used for both the extended and retracted hull configurations.
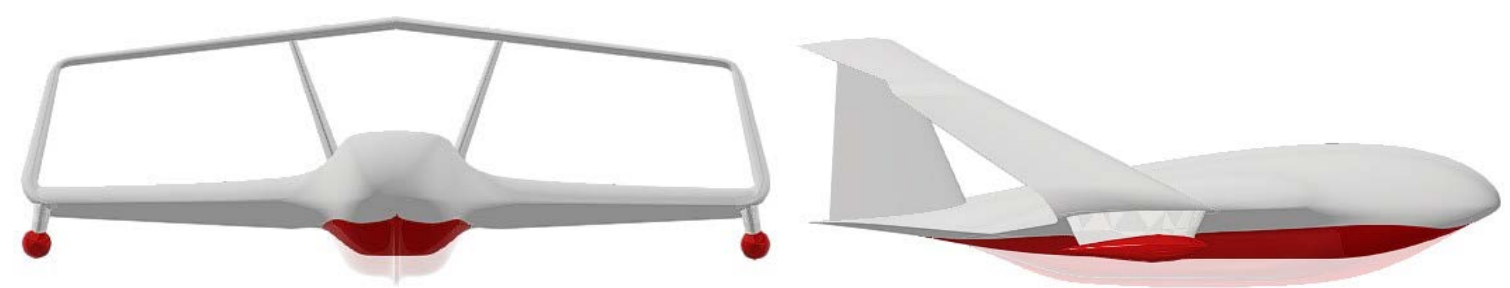

Figure 22. The UGEV platform before and after the extension of the hull.

Following the morphing technologies evaluation studies, a systems selection analysis is carried out. Based on the defined reference mission, a market survey occurred, aiming to identify all the necessary systems for both the flight and mission requirements of the platform. The systems are divided into two main categories. The first one includes the flight systems, while the second one includes all the mission related ones. The following table (Table 7) presents the selected systems.

Table 7. Selected systems for the designed UGEV.

\begin{tabular}{cc}
\hline Flight Systems & Mission Systems \\
\hline Radio communications & Cargo related systems \\
Engines & Hull extension mechanism \\
Fuel system & \\
Cooling system & \\
Electrical systems & \\
Avionics and flight controls & \\
\hline
\end{tabular}

The conceptual design of the proposed UGEV concludes with the estimation of the systems and structure weights and their detailed breakdown. Table 8 includes the identified components and systems for the proposed UGEV, along with their estimated weight.

Table 8. Detailed weight breakdown of the UGEV platform.

\begin{tabular}{cccc}
\hline Component & Number & Weight (kg) & Total Weight (kg) \\
\hline Fuselage & 1 & 50 & 50 \\
Wing & 1 & 49 & 49 \\
Vertical tail & 2 & 14.5 & 29 \\
Horizontal tail & 1 & 26 & 26 \\
Hull mechanism & 1 & 8 & 8 \\
Payload support & 1 & 15 & 15 \\
Flight controls & 6 & 3.3 & 20 \\
Avionics & 1 & 85 & 85 \\
Electrical & 1 & 65 & 65 \\
Cabling & 1 & 20 & 20 \\
Engine mount & 2 & 26 & 52 \\
Engine block & 2 & 102 & 204 \\
Propellers & 2 & 4 & 8 \\
Fuel tanks & 1 & 16 & 16 \\
Fuel lines & 1 & 114 & 4 \\
Fuel & 1 & 300 & 114 \\
Payload & 1 & MTOW & 300 \\
\hline
\end{tabular}


In order to calculate the CG position and MoI matrix of the designed UGEV, a CAD assembly is created incorporating all the identified components and systems. In case a system has no specific/defined volume or shape, a rectangle CAD model is positioned in the assembly regarding its influence on the overall CG position and MoI matrix. The CG position is calculated at $3.05 \mathrm{~m}$ from the nose of the UGEV, along the longitudinal axis, and the principal MoIs around CG are given as $\mathrm{I}_{\mathrm{xx}}=1622 \mathrm{kgm}^{2}, \mathrm{I}_{\mathrm{yy}}=2345 \mathrm{kgm}^{2}$ and $\mathrm{I}_{\mathrm{zz}}=3492$ $\mathrm{kgm}^{2}$. The aforementioned values are calculated based on the estimated MTOW of $1065 \mathrm{~kg}$.

Concerning the control surfaces sizing procedure, based on the data provided by the overall assembly of the GEV (CG position, MoI matrix, engines position, etc.), the following results are presented in Figure 23:

- The elevators are positioned on the upper wing of the design UGEV, which serves as the horizontal stabilizer of the vehicle. They are symmetrical, and they extend at almost $65 \%$ of the outer overall span. The width of the elevator is calculated to be around $30 \%$ of the upper wing chord, leading to tapered control surface (the elevators chord changes with the span).

- The rudders are positioned on the v-tail supports, extending from root to tip. Their chord is $30 \%$ of the vertical stabilizer, resulting in a tapered control surface. Note that the increased rudder authority is critical due to heavily turbulent atmospheric conditions and the application of a two-engine design.

- The ailerons are positioned near the tip of the main wing to increase their effectiveness. They span through the final third of the overall span of the main wing, and their chord is $25 \%$ of the main wing chord.

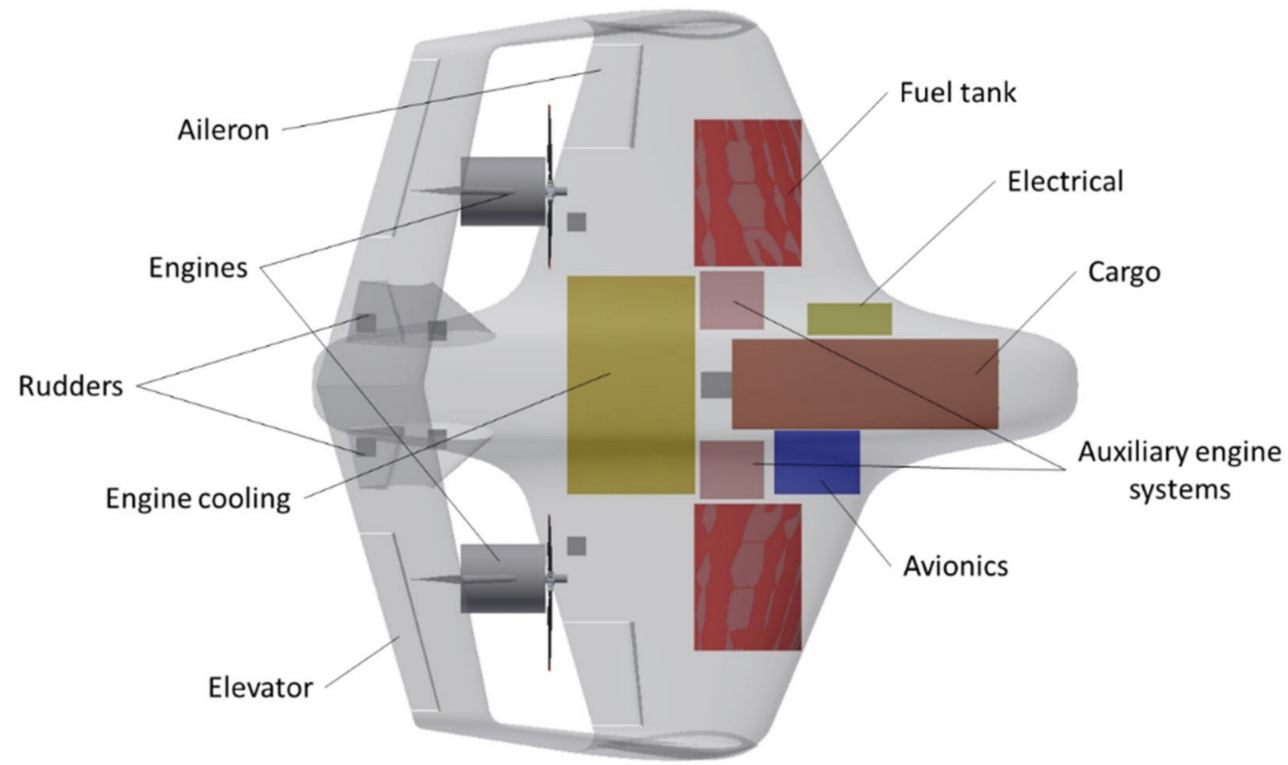

Figure 23. The proposed UGEV systems assembly.

Following, a trim study for a reference cargo airlift mission is conducted, focusing on optimizing the overall CG position of the platform by reducing the necessary trim angle of the control surfaces during cruise. The final trim diagram is presented below (Figure 24). One of the main assumptions concerning the trim studies is that the mission of the designed UGEV initializes with an MTOW of $1065 \mathrm{~kg}$, and at the end of the cruise segment, the fuel $(114 \mathrm{~kg})$ is totally consumed, thus defining the required $\mathrm{C}_{\mathrm{L}}$ and the CG position at the beginning and at the end of the cruise segment. The corresponding $C_{m}$ values are calculated using CFD simulations to the final untrimmed platform. 


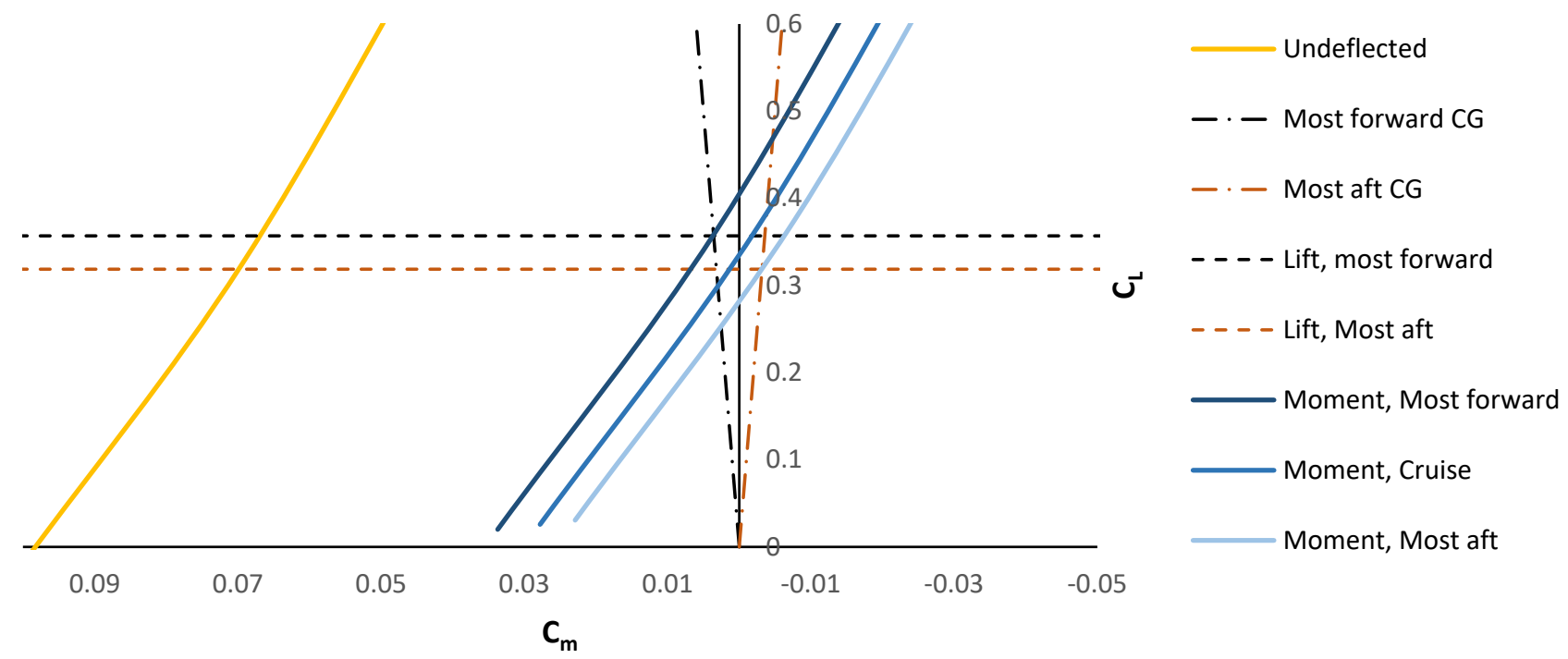

Figure 24. Trim diagram study of the proposed UGEV.

The minimum elevator trim angle for the designed UGEV platform is calculated to be $4.44 \mathrm{deg}$ for the $\mathrm{x}_{\mathrm{CG}}$ position of $3.06 \mathrm{~m}$, measured from the nose of the vehicle (mid-cruise).

\section{Discussion and Conclusions}

The current study presents the conceptual aerodynamic design of a novel UGEV based on in-house analytical tools aided by CFD calculations. Furthermore, actions are taken to improve the initial aerodynamic platform with the use of traditional and novel flow control techniques. The multi-variable approach of this study offers useful conclusions both for GEVs and the combined BWB-BXW platform.

As far as the aerodynamic layout is concerned, a platform which merges the basic characteristics of two novel platform configurations (BWB and BXW) is selected. This hybrid layout, which aims to incorporate the best features from both configurations, enables the vehicle to cope with the adverse flight condition within the atmospheric boundary layer. For the same reason, extended horizontal and vertical tail surfaces are introduced to the design as well as high-mounted engines to increase the clearance from the water surface.

Tubercles and wing fences are studied for a Reynolds number much higher than previously reported in the literature. The CFD calculations prove that the use of such FCTs is beneficiary, even in this extended Reynolds regime. More specifically, the $A_{s} T_{b}$ tubercle setup produced a $30 \mathrm{~kg}$ increase, or $10 \%$ of the total payload. In addition, the wing fence WF2-1 setup can achieve a lift-to-drag ratio (L/D) of $2 \%$ more than the baseline model in cruise conditions. Increasing the efficiency of the platform.

Concerning the morphing technologies evaluation and their possibility of integrating them to the proposed UGEV, the initial literature review indicates that there are many possibly beneficial techniques. A more in-depth analysis, however, suggests that the majority of the identified technologies are too immature to be integrated or incompatible with the selected BWB-BXW platform. The study results in two candidate technologies: the gull shape morphing and the hull morphing. Finally, the gull shape morphing is deemed overly complex and too heavy to be added to the overall design, while the extendable hull morphing technique can be adopted and integrated.

As the final configuration was influenced by designer choices, a non-optimized geometry was produced. Furthermore, the lack of experimental data, as well as the CFD modelling limitations, constrain the accuracy of the current study. However, the initial results are promising enough for the novel UGEV platform to be proposed and considered for further, more accurate, analysis. Therefore, a series of actions for future studies is proposed. For example, a twist implementation study could improve the lift distribution in the main wing. Furthermore, a study about the implementation of a more reflexed main wing airfoil 
could be introduced in order to reduce the necessary trim angle during cruise. Finally, an alternative way to reduce the trim angle would be to parametrically study the distance between the main wing and the tail (tail arm). Overall, the sum of the proposed UGEV design choices (including the introduced BWB-BXW, the vehicle stability characteristics and flow control adaptation) should be validated during preliminary and detail design phases via experimental data and scaled-down models.

Author Contributions: Conceptualization, C.P., D.M. and K.Y.; methodology, C.P. and D.M.; validation, C.P. and D.M.; investigation, C.P. and D.M.; resources, K.Y.; writing-original draft preparation, C.P. and D.M.; writing-review and editing, K.Y.; visualization, C.P. and D.M.; supervision, K.Y.; project administration, K.Y.; funding acquisition, K.Y. All authors have read and agreed to the published version of the manuscript.

Funding: This research is co-financed by Greece and the European Union (European Social FundESF) through the Operational Program «Human Resources Development, Education and Lifelong Learning 2014-2020» in the context of the project "HELTFLOW" (MIS 5047813).

Institutional Review Board Statement: Not applicable.

Informed Consent Statement: Not applicable.

Data Availability Statement: Data sharing not applicable.

Acknowledgments: This research is carried out in the context of the project "Hellenic Transport UAV Flying Low over Water (HELTFLOW MIS 5047813)" under the call for proposals "CCI2014GR059OP001". The project is co-financed by Greece and the European Union (European Social Fund-ESF) by the Operational Program «Human Resources Development, Education and Lifelong Learning 2014-2020».

Conflicts of Interest: The authors declare no conflict of interest.

\section{References}

1. Yun, L.; Bliault, A.; Doo, J. WIG Craft and Ekranoplan: Ground Effect Craft Technology; Springer: Boston, MA, USA, 2010; ISBN 9781441900418 .

2. Arany, L.; Bhattacharya, S.; Macdonald, J.; Hogan, S.J. Simplified critical mudline bending moment spectra of offshore wind turbine support structures. Wind Energy 2015, 18, 2171-2197. [CrossRef]

3. Rozhdestvensky, K.V. Aerodynamics of a Lifting System in Extreme Ground Effect; Springer: Cham, Switzerland, 2000; ISBN 9783642085567.

4. Halloran, M.; O'Meara, S. Wing in Ground Effect Craft Review; DSTO Aeronautical and Maritime Research Laboratory: Melbourne, Australia, 1999.

5. Rozhdestvensky, K.V. Wing-in-ground effect vehicles. Prog. Aerosp. Sci. 2006, 42, 211-283. [CrossRef]

6. Austin, R. Unmanned Aircraft Systems; Wiley: Hoboken, NJ, USA, 2010; ISBN 9780470058190.

7. Kaparos, P.; Papadopoulos, C.; Yakinthos, K. Conceptual design methodology of a box wing aircraft: A novel commercial airliner. Proc. Inst. Mech. Eng. Part G J. Aerosp. Eng. 2018, 232, 2651-2662. [CrossRef]

8. Panagiotou, P.; Fotiadis-Karras, S.; Yakinthos, K. Conceptual design of a Blended Wing Body MALE UAV. Aerosp. Sci. Technol. 2018, 73, 32-47. [CrossRef]

9. Amir, M.A.U.; Maimun, A.; Mat, S.; Saad, M.R.; Zarim, M.A. Wing in Ground Effect Craft: A Review of the State of Current Stability Knowledge. In Proceedings of the International Conference on Ocean Mechanical and Aerospace for Scientists and Engineers (OMAse), Terengganu, Malaysia, 7-8 November 2016; pp. 277-290.

10. Brown, M.; Vos, R. Conceptual design and evaluation of blended-wing-body aircraft. In Proceedings of the 2018 AIAA Aerospace Sciences Meeting, Kissimmee, FL, USA, 8-12 January 2018. [CrossRef]

11. Wolkovitch, J. Joined Wing: An Overview. J. Aircr. 1985, 23, 161-178. [CrossRef]

12. Dickson, J.K.; Sutton, F.B. The Effect of Wing Fences on the Longitudinal Characteristics at Mach Numbers up to 0.92 of a Wing-FuselageTail Combination Having a 400 Sweptback Wing with Naca 64a Thickness Distribution; National Advisory Committee for Aeronautics: Washington, DC, USA, 1955.

13. Boltz, F.W.; Shibata, H.H. Pressure Distribution at Mach Numbers up to 0.90 on a Cambered and Twisted Wing Having 40 of Sweepback and an Aspect Ratio of 10, Including the Effects of Fences; National Advisory Committee for Aeronautics: Washington, DC, USA, 1953.

14. Newsom, W.A.; Satran, D.R.; Johnson, J.L. Effects of Wing-Leading-Edge Modifications on a Full-Scale, Low-Wing General Aviation Airplane; NASA Technical Paper 2011; The National Aeronautics and Space Administration (NASA): Washington, DC, USA, 1982.

15. Bray, R.S. The Effects of Fences on the High-Speed Longitudinal Stability of a Swept-Wing Airplane; National Advisory Committee for Aeronautics: Washington, DC, USA, 1953.

16. Fish, F.E.; Battle, J.M. Hydrodynamic design of the humpback whale flipper. J. Morphol. 1995, 225, 51-60. [CrossRef] 
17. Miklosovic, D.S.; Murray, M.M.; Howle, L.E. Experimental Evaluation of Sinusoidal Leading Edges. J. Aircr. 2007, 44, 1404-1408. [CrossRef]

18. Aftab, S.M.A.; Razak, N.A.; Mohd Rafie, A.S.; Ahmad, K.A. Mimicking the humpback whale: An aerodynamic perspective. Prog. Aerosp. Sci. 2016, 84, 48-69. [CrossRef]

19. Gopinathan, V.T.; Bruce Ralphin Rose, J. Aerodynamics with state-of-the-art bioinspired technology: Tubercles of humpback whale. Proc. Inst. Mech. Eng. Part G J. Aerosp. Eng. 2021, 235, 2359-2377. [CrossRef]

20. Papadopoulos, C.; Katsiadramis, V.; Yakinthos, K. Influence of tubercles' spanwise distribution on swept wings for unmanned aerial vehicles. Proc. Inst. Mech. Eng. Part G J. Aerosp. Eng. 2021, 235, 95-103. [CrossRef]

21. Fish, F.E.; Weber, P.W.; Murray, M.M.; Howle, L.E. The tubercles on humpback whales' flippers: Application of bio-inspired technology. Integr. Comp. Biol. 2011, 51, 203-213. [CrossRef]

22. Wei, Z.; New, T.H.; Lian, L.; Zhang, Y. Leading-edge tubercles delay flow separation for a tapered swept-back wing at very low Reynolds number. Ocean Eng. 2019, 181, 173-184. [CrossRef]

23. Barbarino, S.; Pecora, R.; Lecce, L.; Concilio, A.; Ameduri, S.; Calvi, E. A novel SMA-based concept for airfoil structural morphing. J. Mater. Eng. Perform. 2009, 18, 696-705. [CrossRef]

24. Barbarino, S.; Bilgen, O.; Ajaj, R.M.; Friswell, M.I.; Inman, D.J. A review of morphing aircraft. J. Intell. Mater. Syst. Struct. 2011, 22, 823-877. [CrossRef]

25. Li, D.; Zhao, S.; Da Ronch, A.; Xiang, J.; Drofelnik, J.; Li, Y.; Zhang, L.; Wu, Y.; Kintscher, M.; Monner, H.P.; et al. A review of modelling and analysis of morphing wings. Prog. Aerosp. Sci. 2018, 100, 46-62. [CrossRef]

26. Abdulrahim, M.; Lind, R. Flight testing and response characteristics of a variable Gull-Wing morphing aircraft. AIAA Guid. Navig. Control Conf. Exhib. 2004, 5113. [CrossRef]

27. Raymer, D. Aircraft Design: A Conceptual Approach, 6th ed.; American Institute of Aeronautics and Astronautics: Reston, VA, USA, 2018. [CrossRef]

28. Roskam, D.J. Airplane Design Part VI: Preliminary Calculation of Aerodynamic Thrust and Power Characteristics; Design, Analysis and Research Corporation (DARcorporation): Lawrence, KS, USA, 1987; pp. 21-98.

29. Papadopoulos, C.; Mitridis, D.; Yakinthos, K. Conceptual design of a novel unmanned Ground Effect Vehicle. IOP Conf. Ser. Mater. Sci. Eng. 2021, 1024, 012058. [CrossRef]

30. Emmanouil, G.; Galanis, G.; Kalogeri, C.; Zodiatis, G.; Kallos, G. 10-year high resolution study of wind, sea waves and wave energy assessment in the Greek offshore areas. Renew. Energy 2016, 90, 399-419. [CrossRef]

31. Sadraey, M.H. Design of Unmanned Aerial Systems; Wiley: Manchester, NH, USA, 2020; ISBN 9781119508700.

32. Menter, F.R. Two-equation eddy-viscosity turbulence models for engineering applications. AIAA J. 1994, 32, 1598-1605. [CrossRef]

33. Menter, F.R.; Langtry, R.B.; Likki, S.R.; Suzen, Y.B.; Huang, P.G.; Völker, S. A correlation-based transition model using local variables-Part I: Model formulation. J. Turbomach. 2006, 128, 413-422. [CrossRef]

34. Lohry, M.W.; Clifton, D.; Martinelli, L. Characterization and design of tubercle leading-edge wings. In Proceedings of the 7th International Conference on Computational Fluid Dynamics (ICCFD), Mauna Lani Bay, HI, USA, 9-13 July 2012 ; pp. 1-11.

35. Swanson, T.; Isaac, K.M. Biologically inspired wing leading edge for enhanced wind turbine and aircraft performance. In Proceedings of the 6th AIAA Theoretical Fluid Mechanics Conference, Honolulu, HI, USA, 27-30 June 2011; pp. 1-10. [CrossRef]

36. Dropkin, A.; Custodio, D.; Henoch, C.W.; Johari, H. Computation of flowfield around an airfoil with leading-edge protuberances. J. Aircr. 2012, 49, 1345-1355. [CrossRef]

37. Gross, A.; Fasel, H.F. Numerical Investigation of Passive Separation Control for an Airfoil at Low-Reynolds-Number Conditions. AIAA J. 2013, 51, 1553-1565. [CrossRef]

38. Bolzon, M.D.; Kelso, R.M.; Arjomandi, M. Tubercles and Their Applications. J. Aerosp. Eng. 2016, 29, 04015013. [CrossRef]

39. Cerón-Muñoz, H.D.; Diaz-Izquierdo, D.O.; Bravo-Mosquera, P.D.; Catalano, F.M.; De Santana, L.D. Experimental analyses of droop, wingtips and fences on a BWB model. In Proceedings of the 30th Congress of the International Council of the Aeronautical Sciences (ICAS 2016), Daejeon, Korea, 25-30 September 2016; pp. 1-7.

40. Gudmundsson, S. APPENDIX C3: Design of Seaplanes. In General Aviation Aircraft Design: Applied Methods and Procedures; Elsevier: Amsterdam, The Netherlands, 2013; pp. 1-32. 